\title{
Highly Selective Synthesis of 2-tert-Butoxy-1-Arylethanones via Copper(I)-Catalyzed Oxidation/tert-Butoxylation of Aryl Olefins with TBHP
}

Jiantao Zhang, Duoduo Xiao*, Hua Tan, WeibingLiu*

*College of Chemistry, Guangdong University of Petrochemical Technology, Guandu Road, Maoming 525000, P. R. China; Email address:1wb409@gdupt.edu.cn; dd.xiao@gdupt.edu.cn

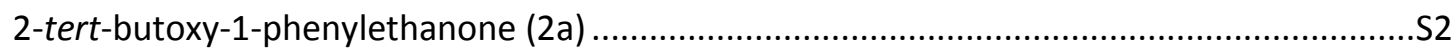

2-tert-butoxy-1-(4-tert-butoxyphenyl)ethanone (2b) ........................................................ 4

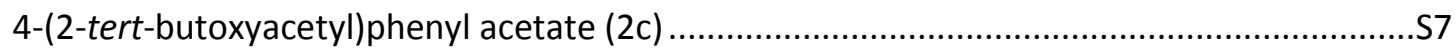

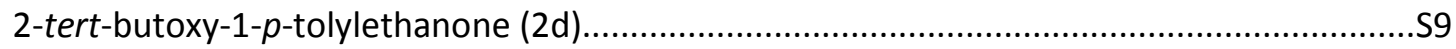

2-tert-butoxy-1-(4-tert-butylphenyl)ethanone (2e) ........................................................S11

2-tert-butoxy-1-(4-phenylphenyl)ethanone (2f) …….......................................................

2-tert-butoxy-1-(4-(chloromethyl)phenyl)ethanone (2g) …..................................................

2-tert-butoxy-1-(4-fluorophenyl)ethanone (2h) ………................................................ 18

2-tert-butoxy-1-(4-chlorophenyl)ethanone (2i) ..................................................................S20

2-tert-butoxy-1-(4-(trifluoromethyl)phenyl)ethanone (2j) ...............................................S22

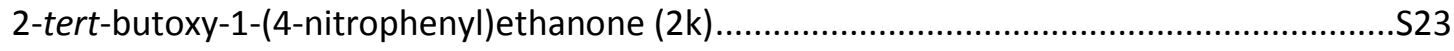

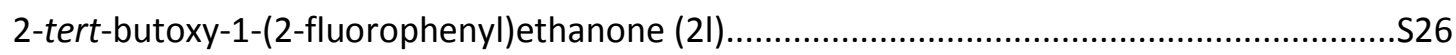

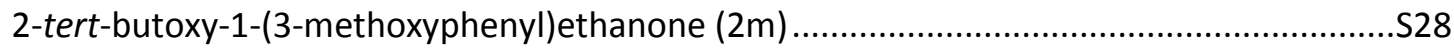

2-tert-butoxy-1-m-tolylethanone (2n) ........................................................................... 330

2-tert-butoxy-1-(3-fluorophenyl)ethanone (20) ……...........................................................S33

2-tert-butoxy-1-(3-chlorophenyl)ethanone (2p) ………......................................................535

2-tert-butoxy-1-(naphthalen-3-yl)ethanone (2q) …........................................................S37

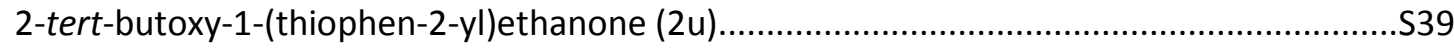

1-((E)-3-(tert-butylperoxy)prop-1-enyl)benzene (5a).................................................. 44

1-((E)-3-(tert-butylperoxy)prop-1-enyl)-4-fluorobenzene (5b) ..........................................S43

1-((E)-3-(tert-butylperoxy)prop-1-enyl)-4-(trifluoromethyl)benzene (5c) ............................S45

1-((E)-3-(tert-butylperoxy)prop-1-enyl)-2-methoxybenzene (5d) ........................................S47 


\section{NMR spectra}

\section{2-tert-butoxy-1-phenylethanone (2a) ${ }^{1}$}

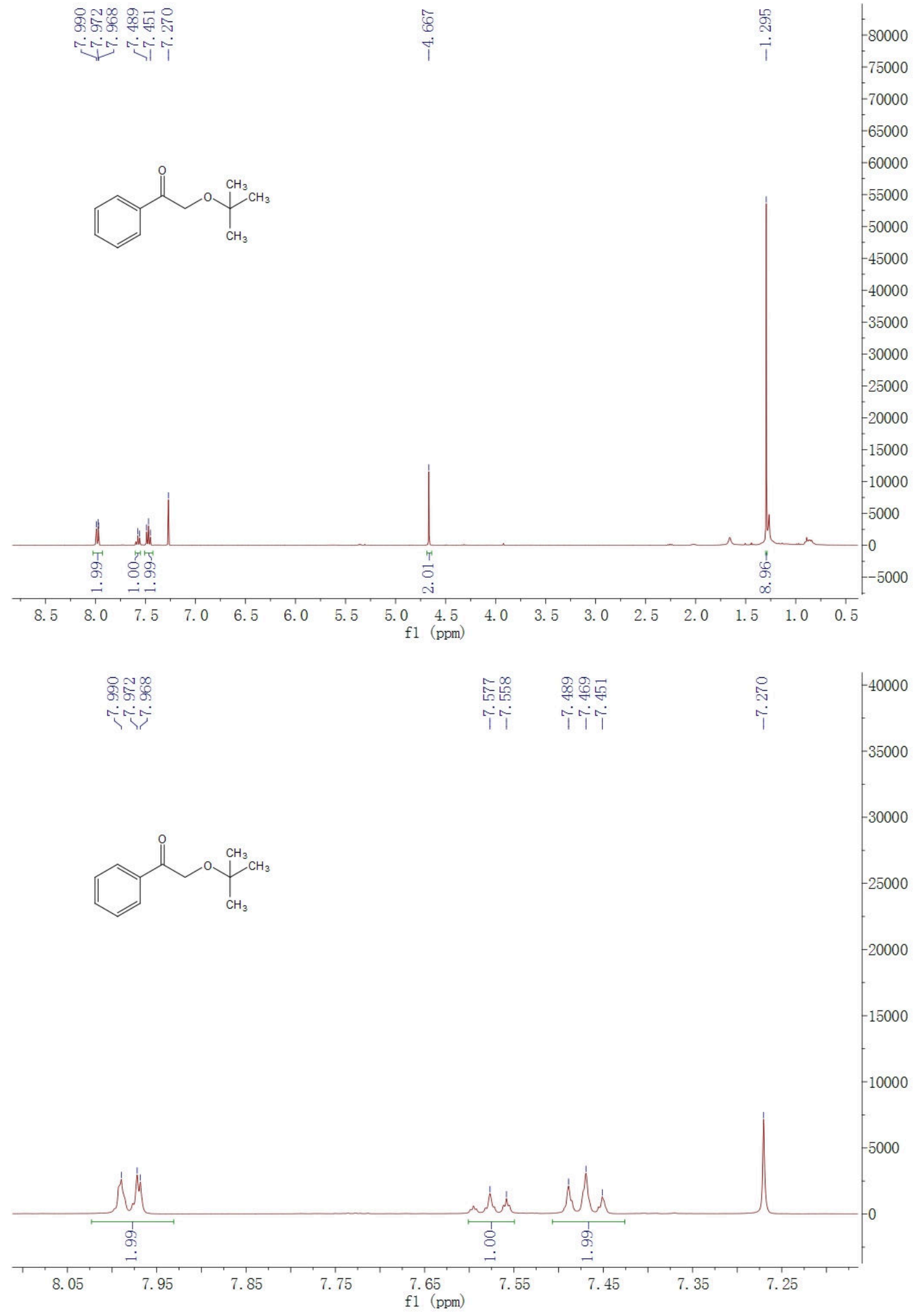




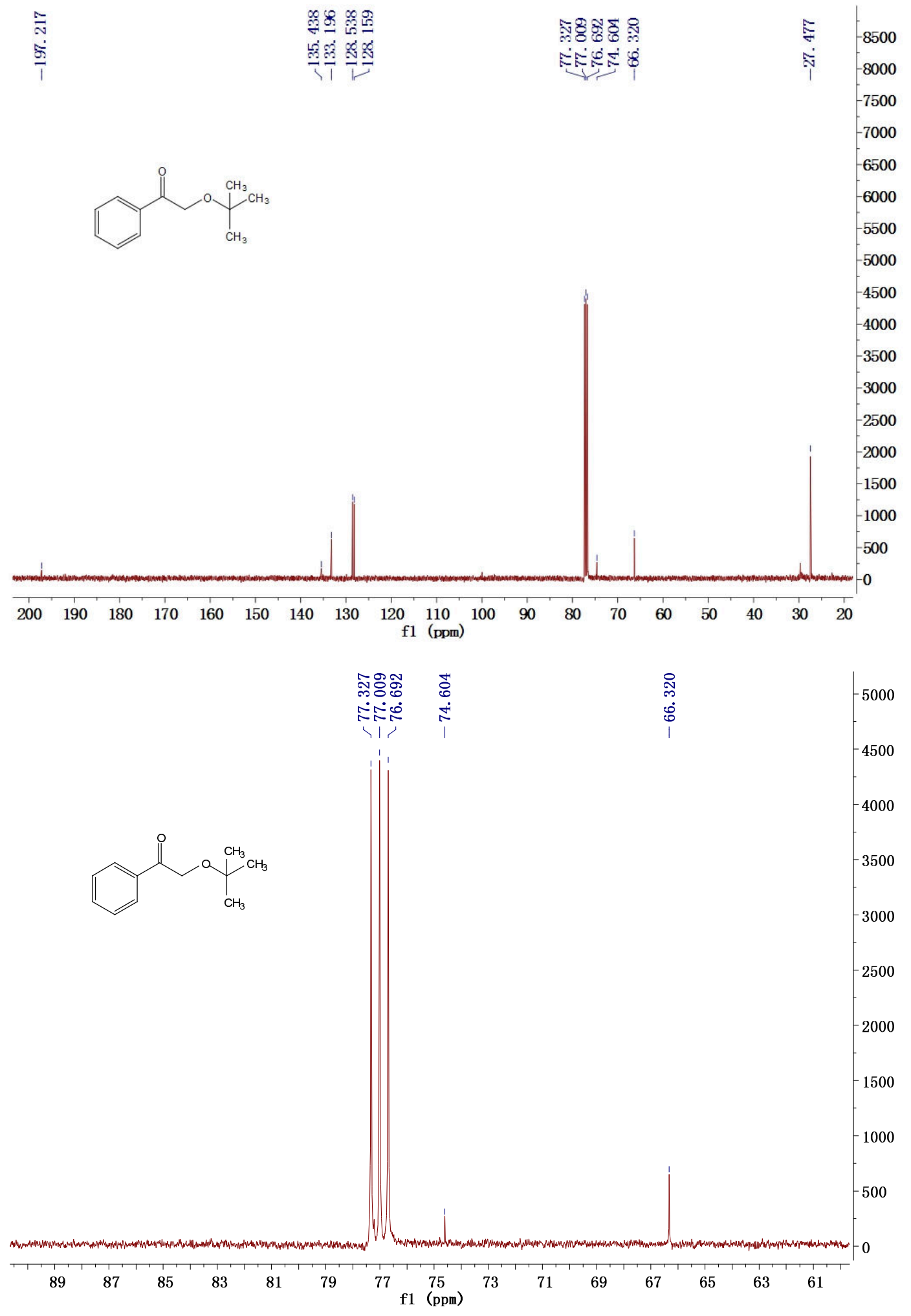




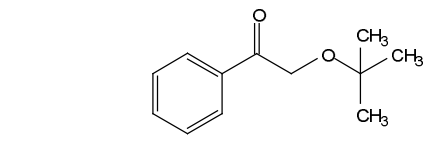

\section{2-tert-butoxy-1-(4-tert-butoxyphenyl)ethanone (2b)}

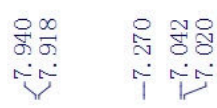

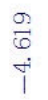

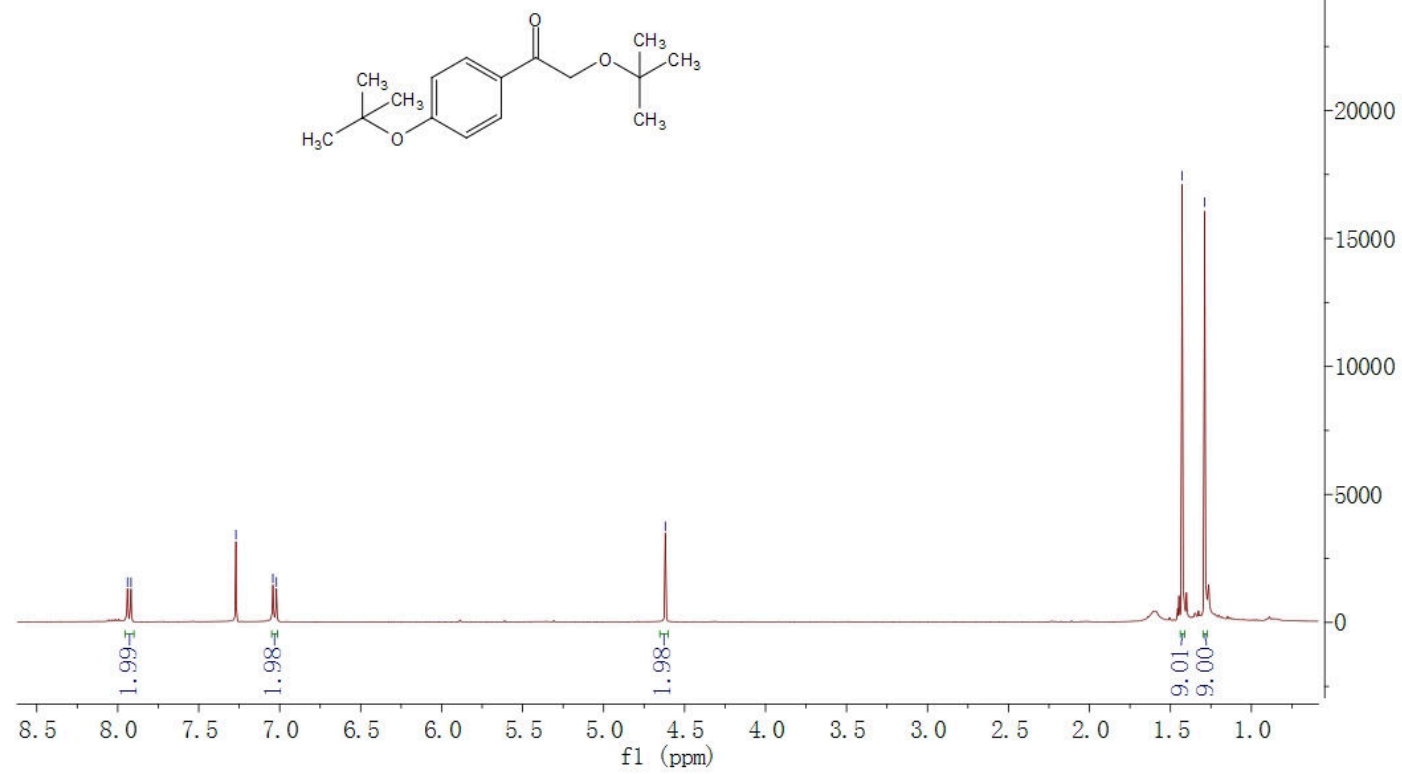



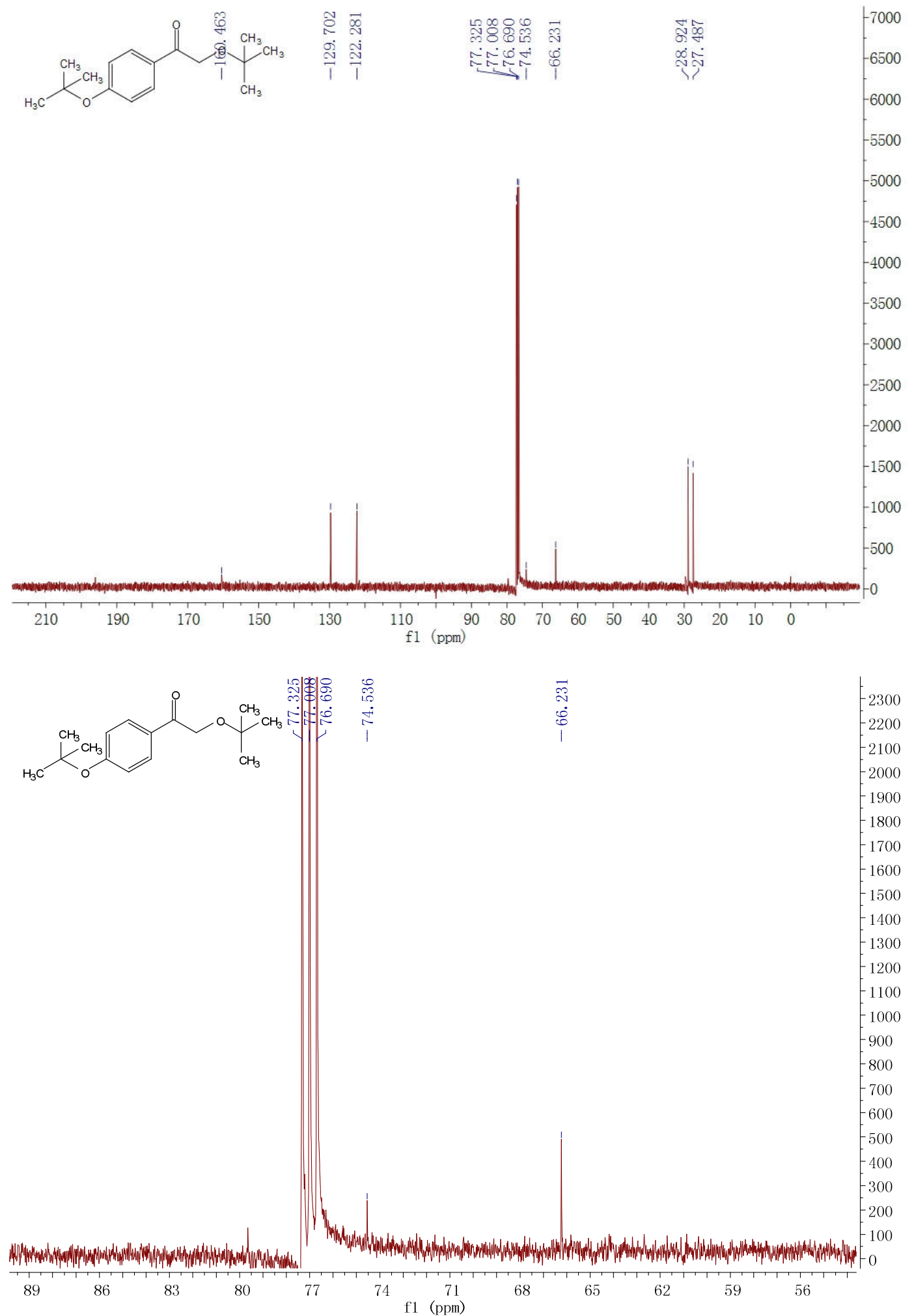

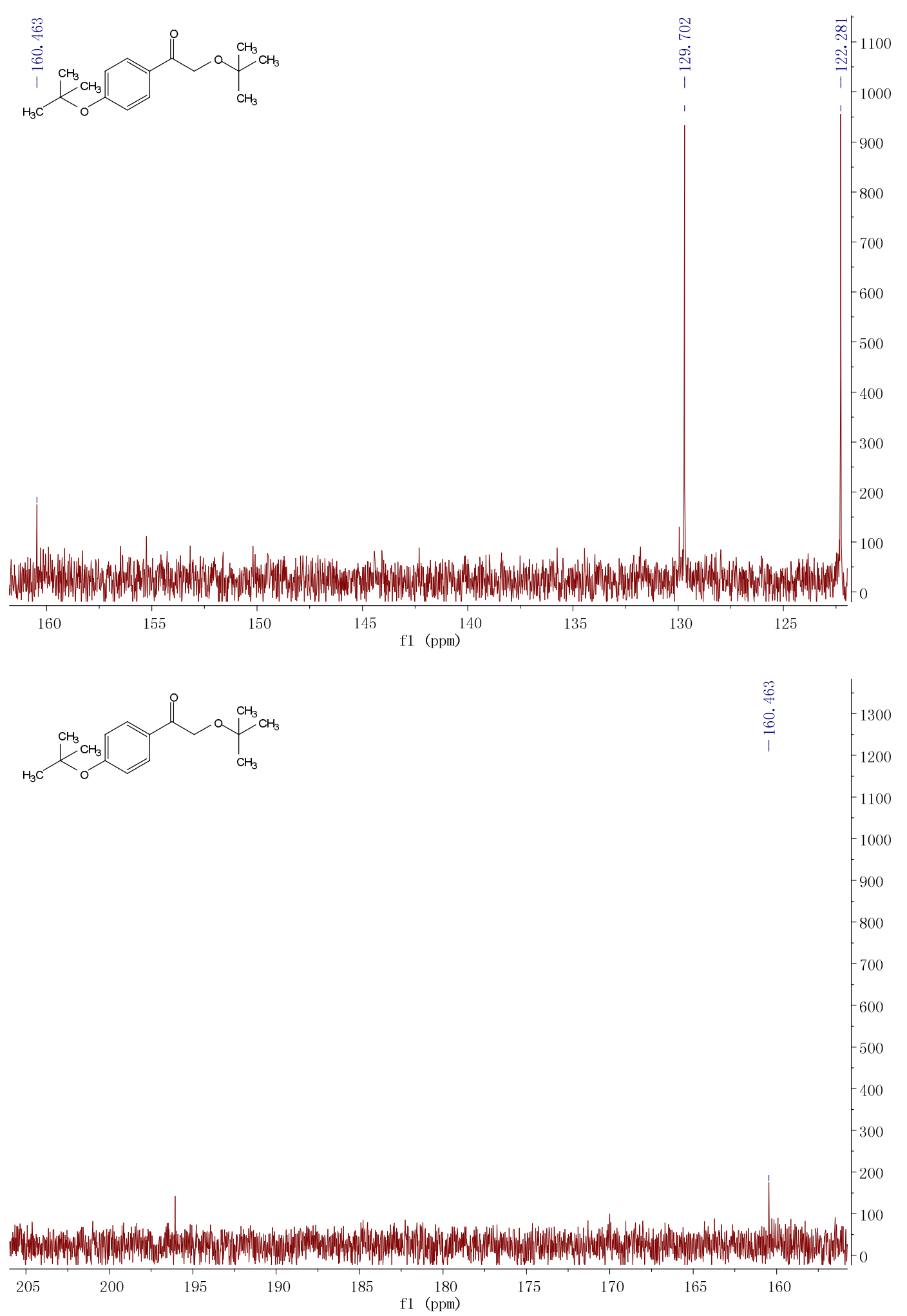
4-(2-tert-butoxyacetyl)phenyl acetate (2c)

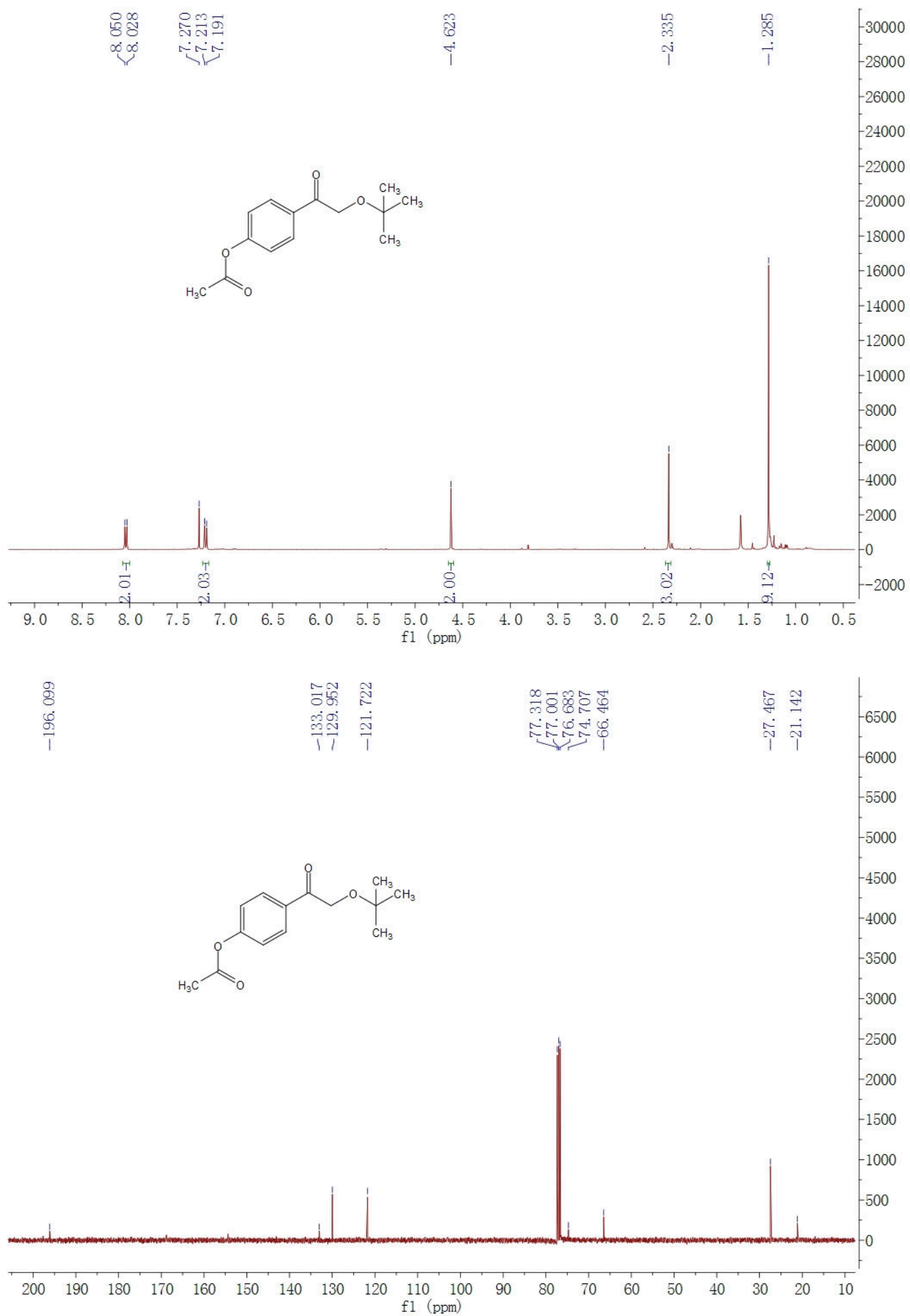




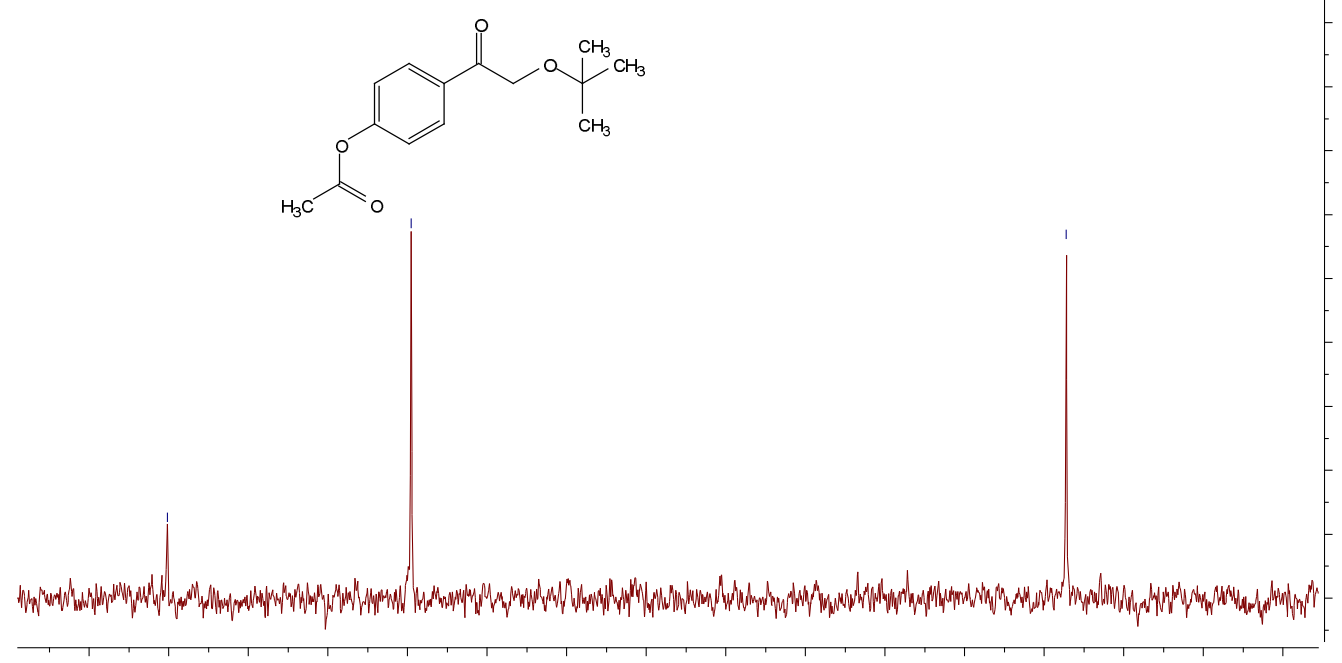

\begin{tabular}{l}
8 \\
8 \\
0 \\
8 \\
\hline
\end{tabular}
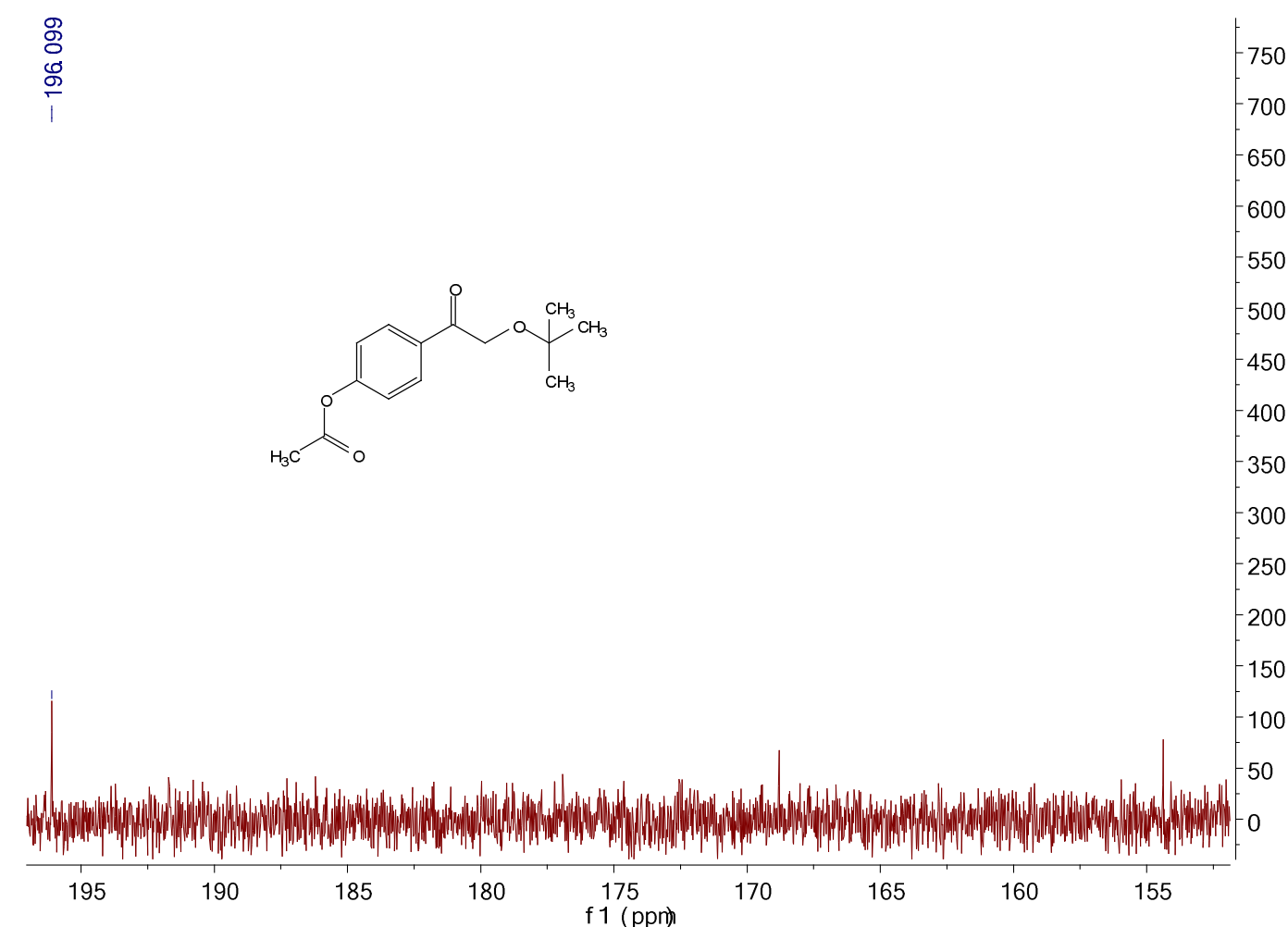
2-tert-butoxy-1-p-tolylethanone (2d)

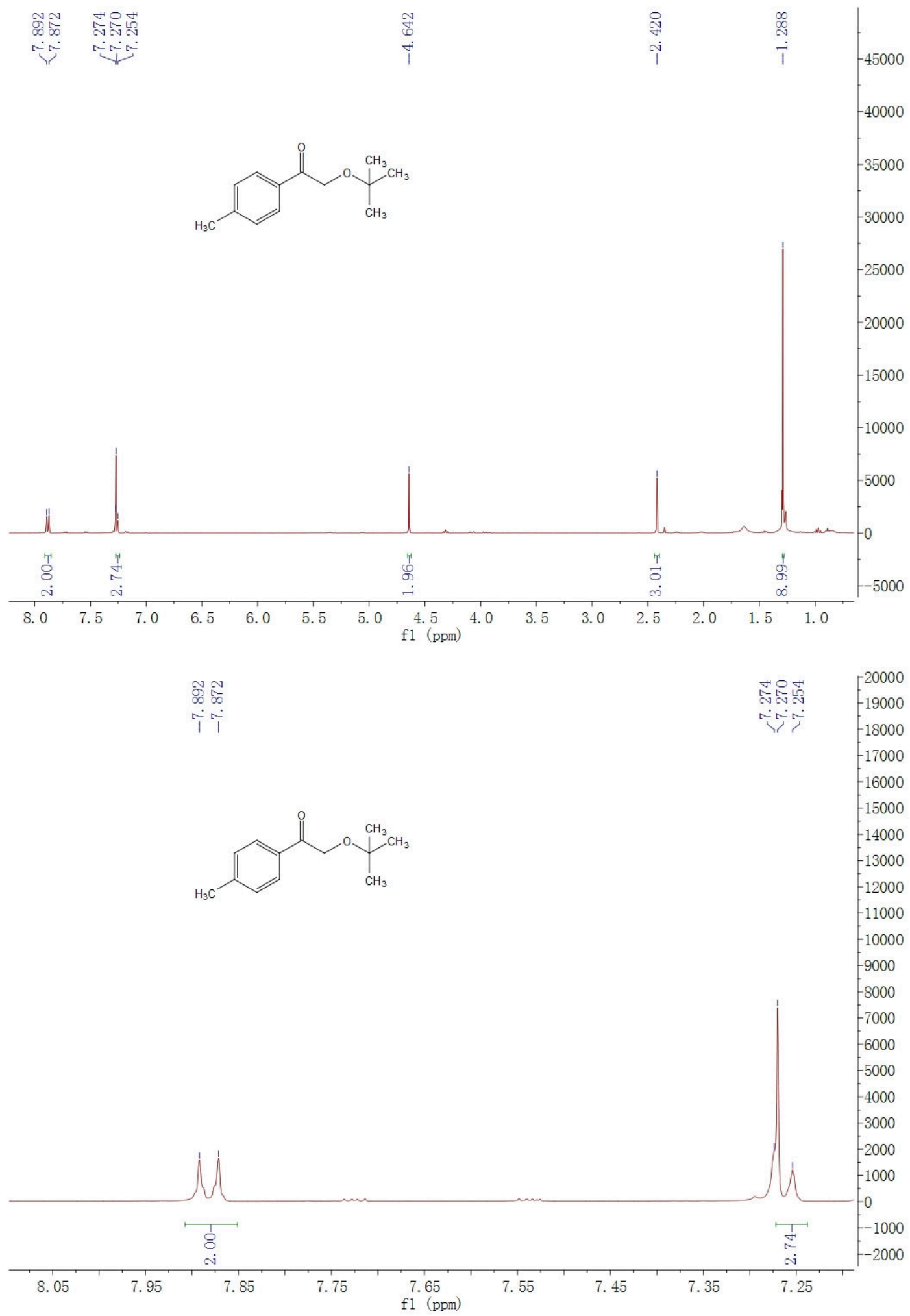




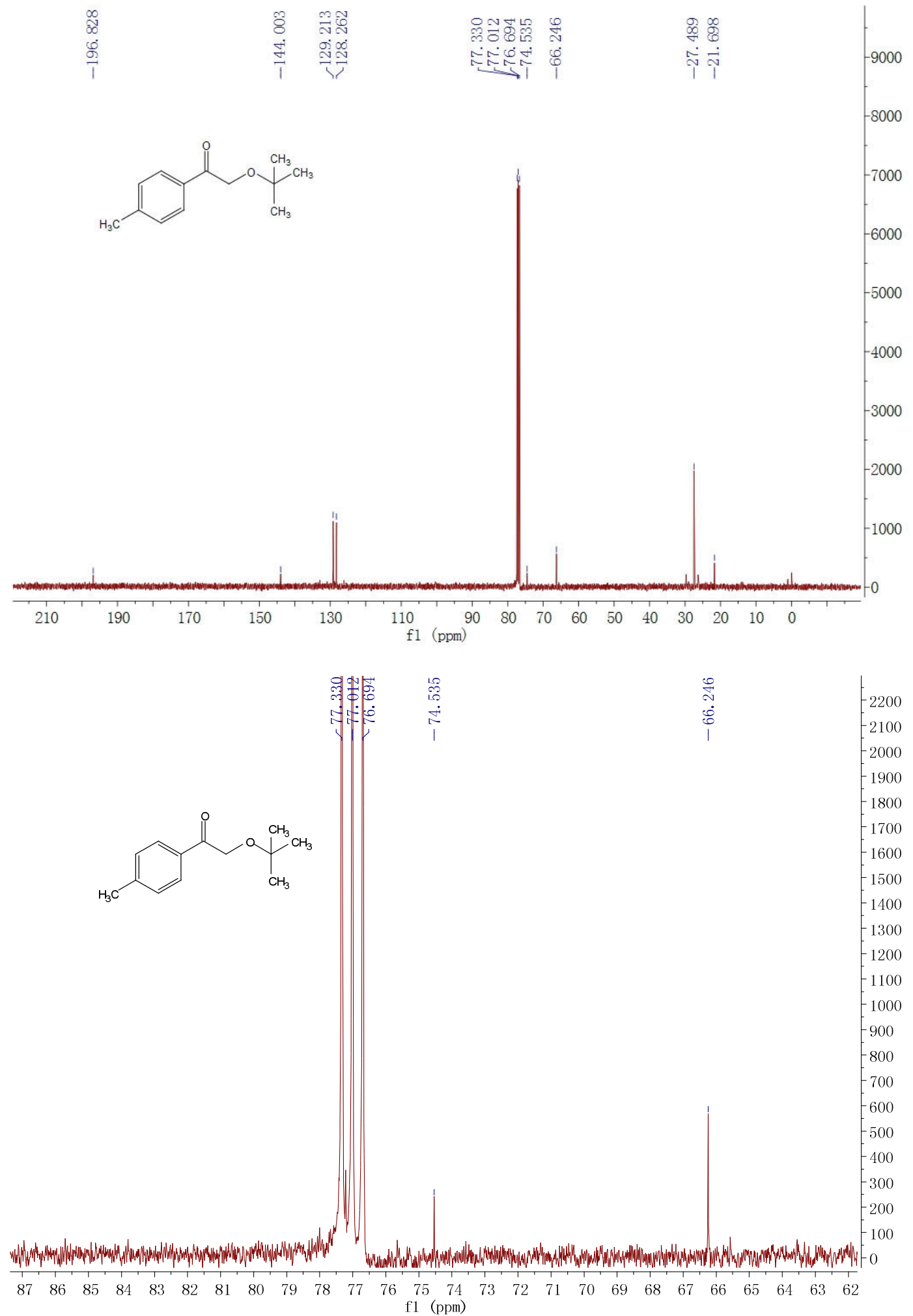




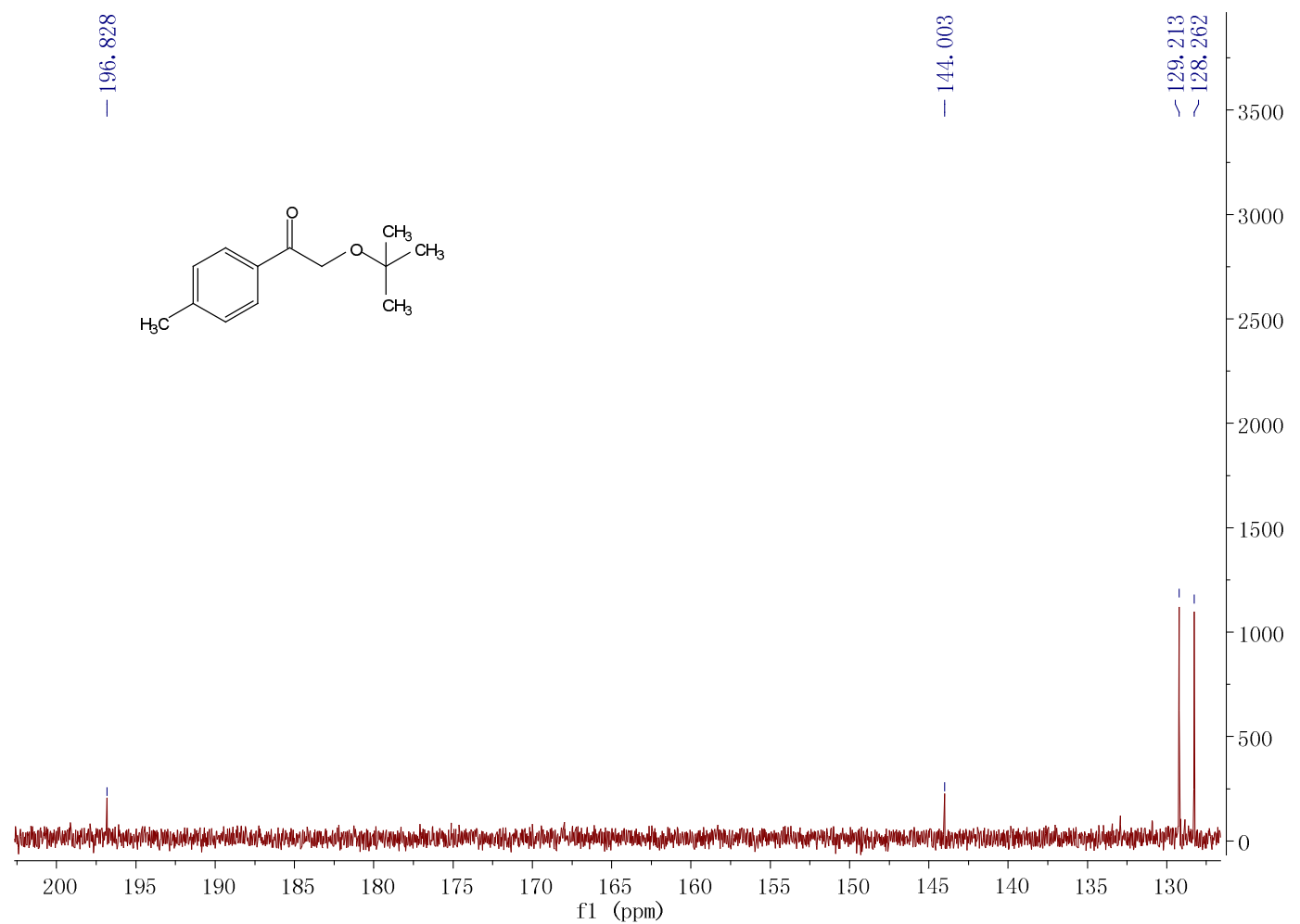

2-tert-butoxy-1-(4-tert-butylphenyl)ethanone (2e)

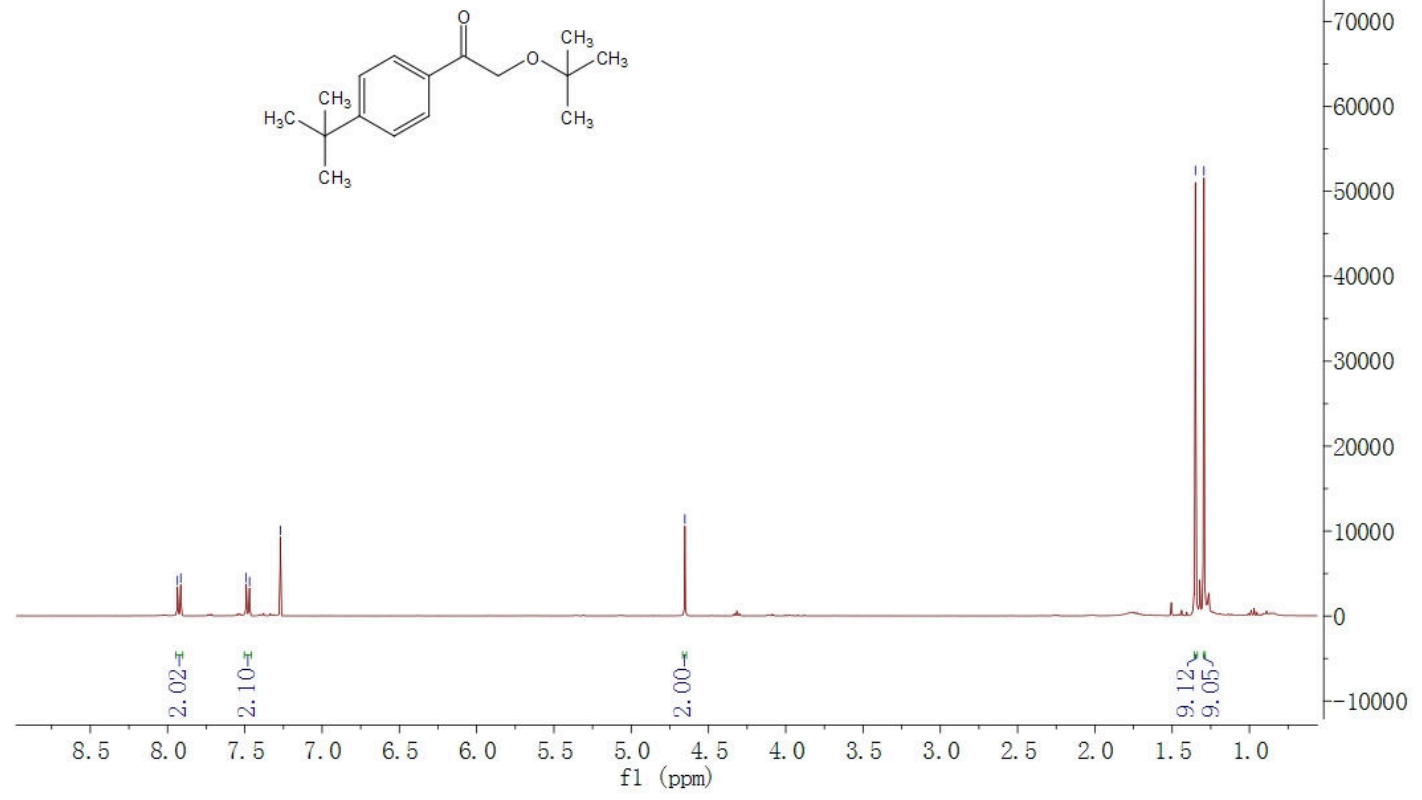




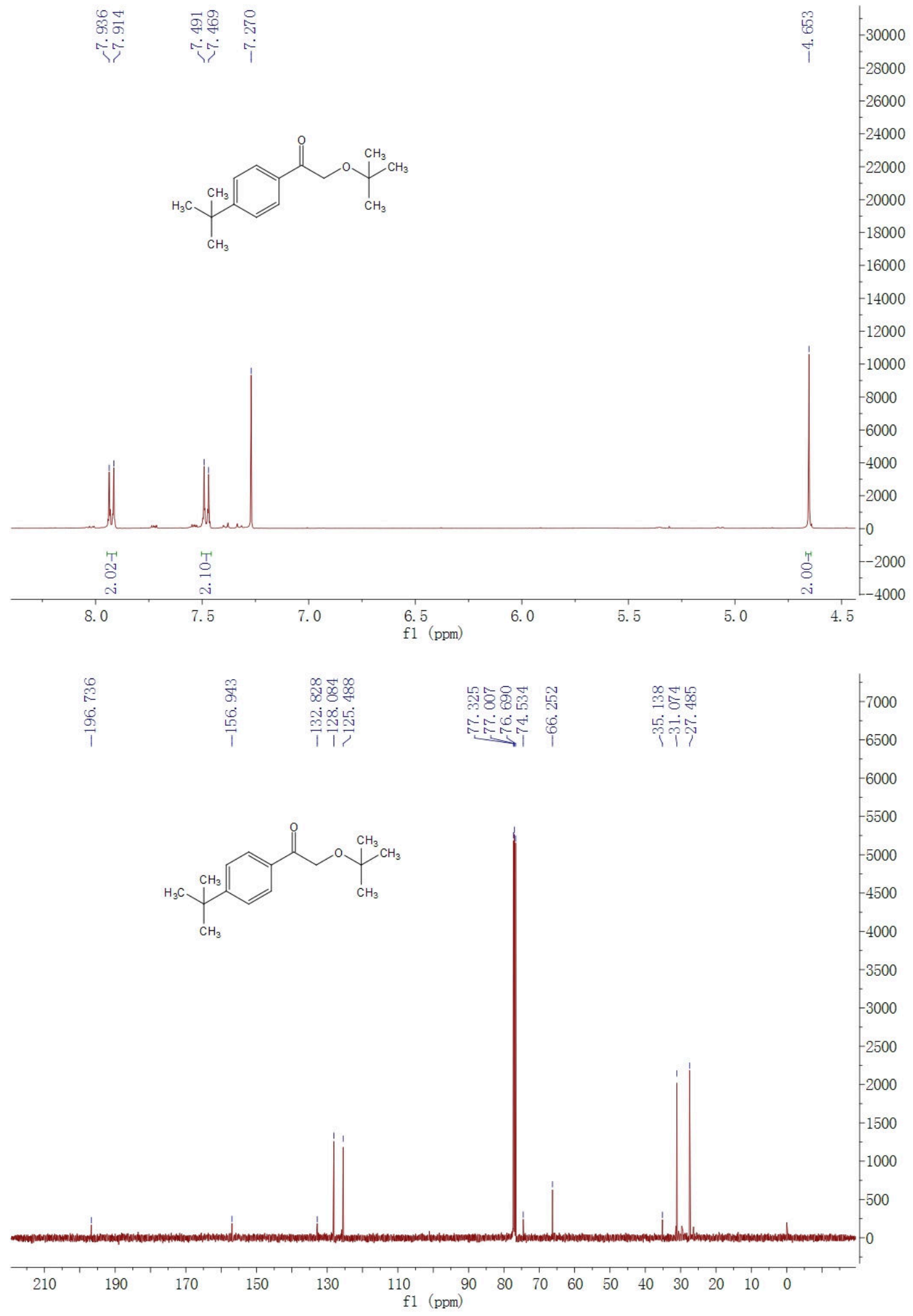



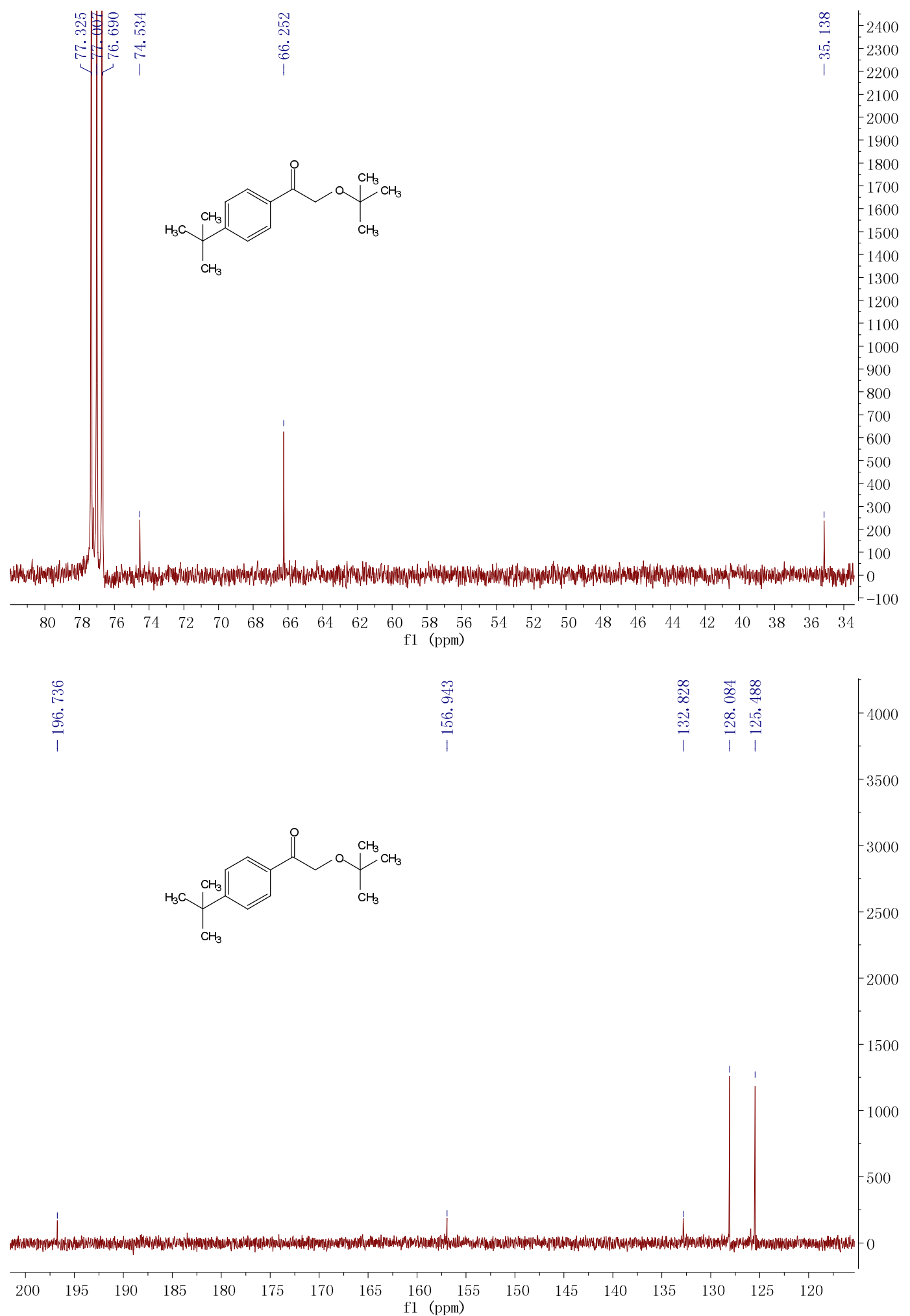
2-tert-butoxy-1-(4-phenylphenyl)ethanone (2f)

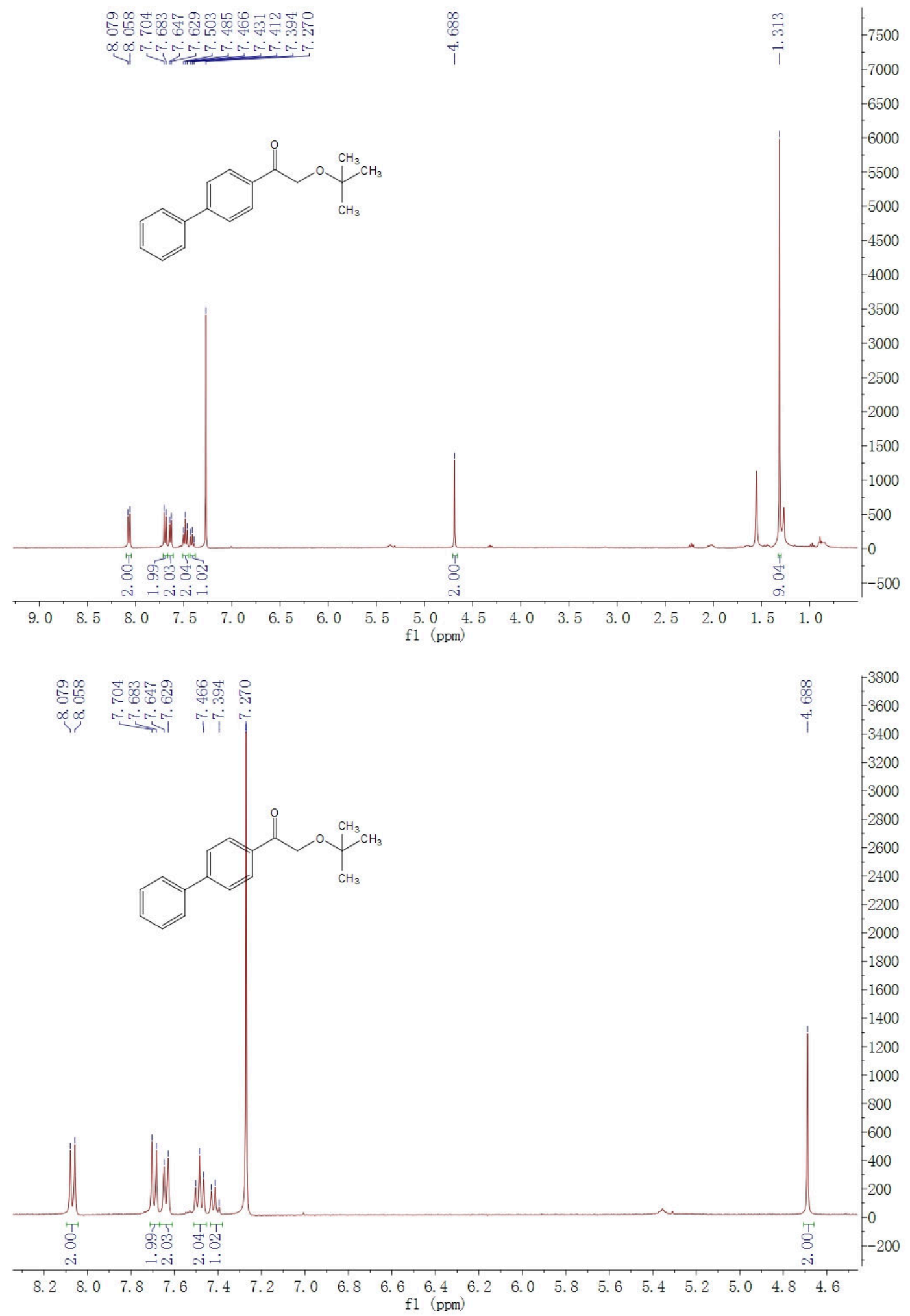



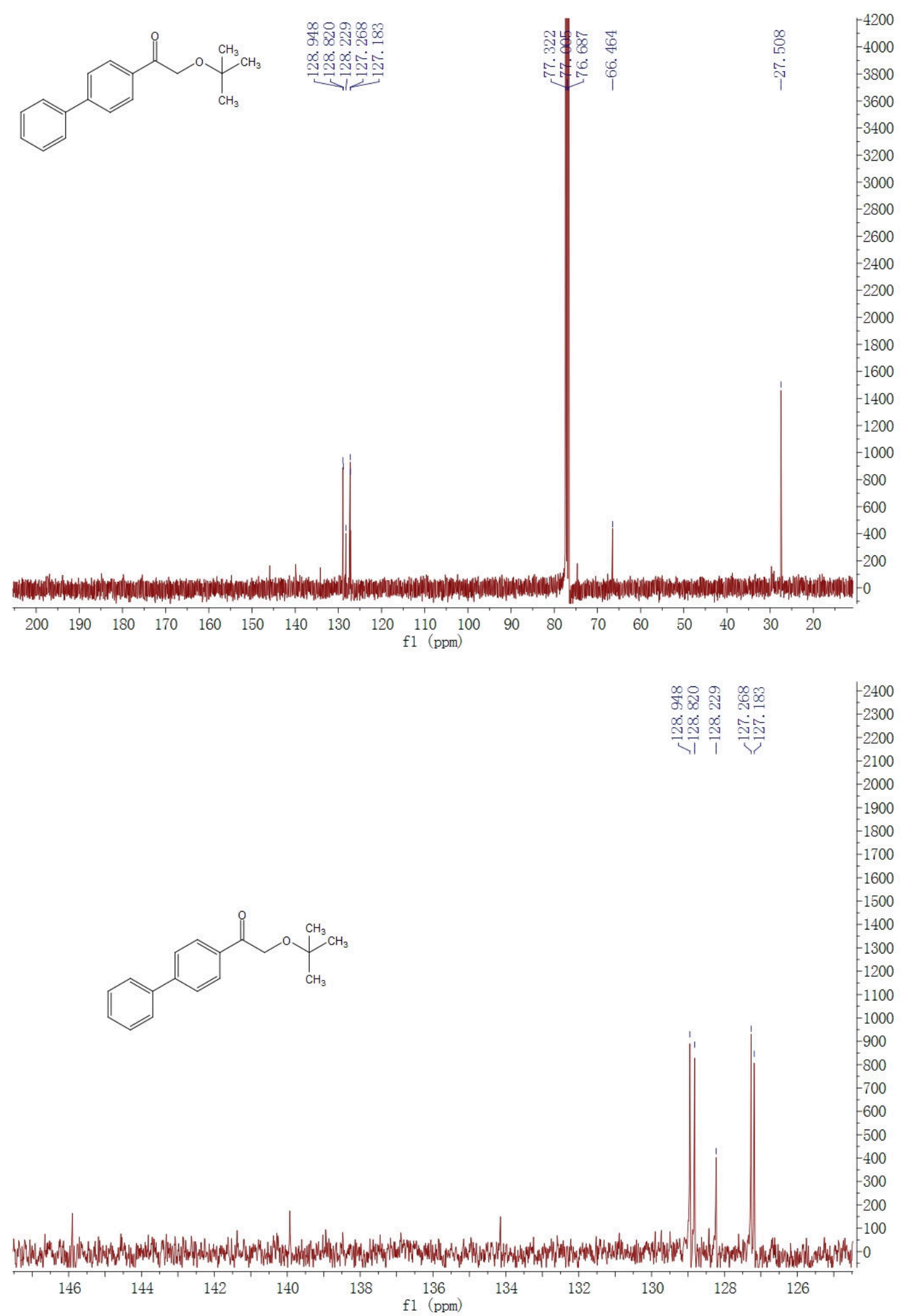
2-tert-butoxy-1-(4-(chloromethyl)phenyl)ethanone (2g)

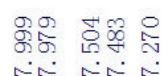

छ응.

त्त्रत
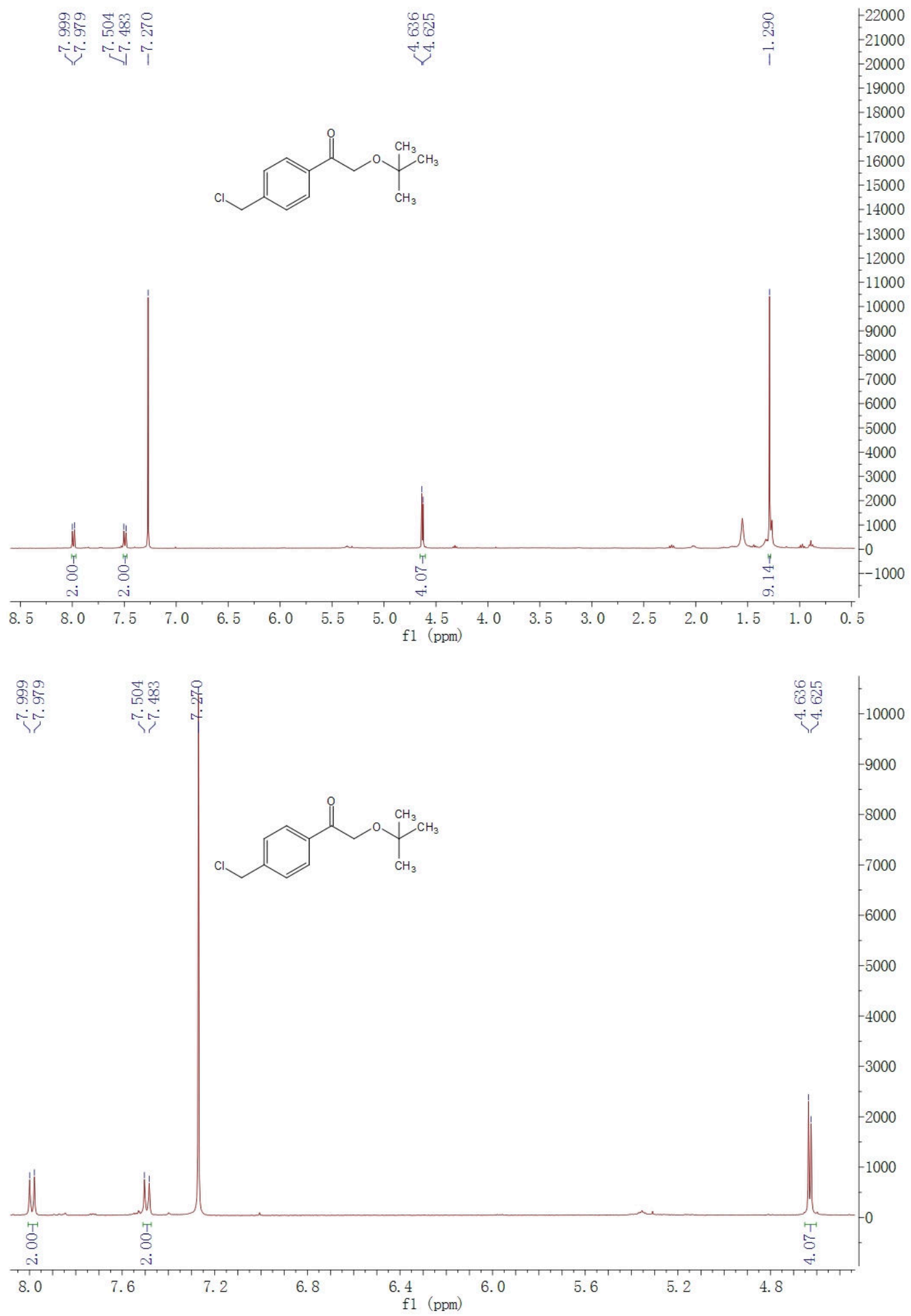

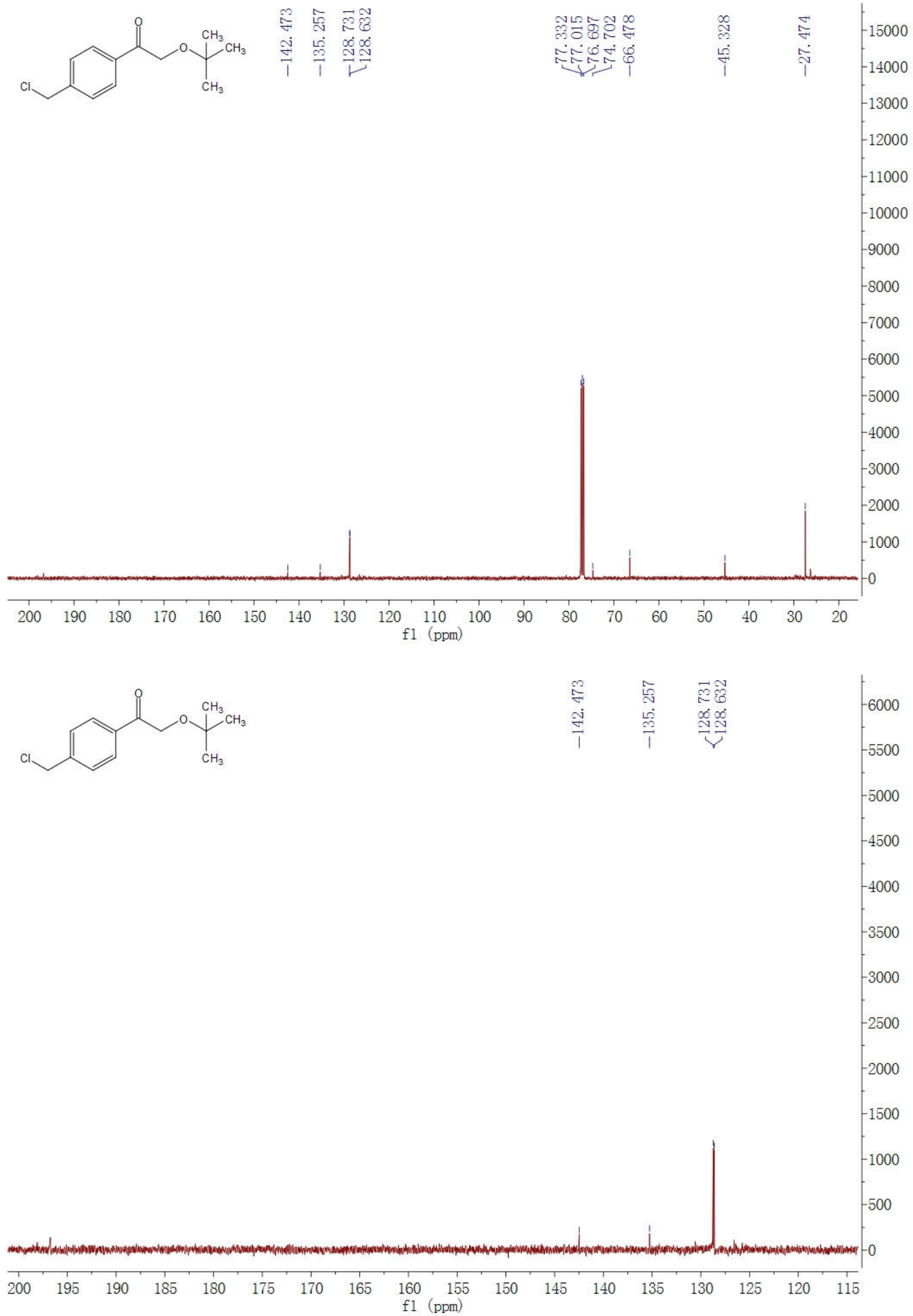
2-tert-butoxy-1-(4-fluorophenyl)ethanone (2h)

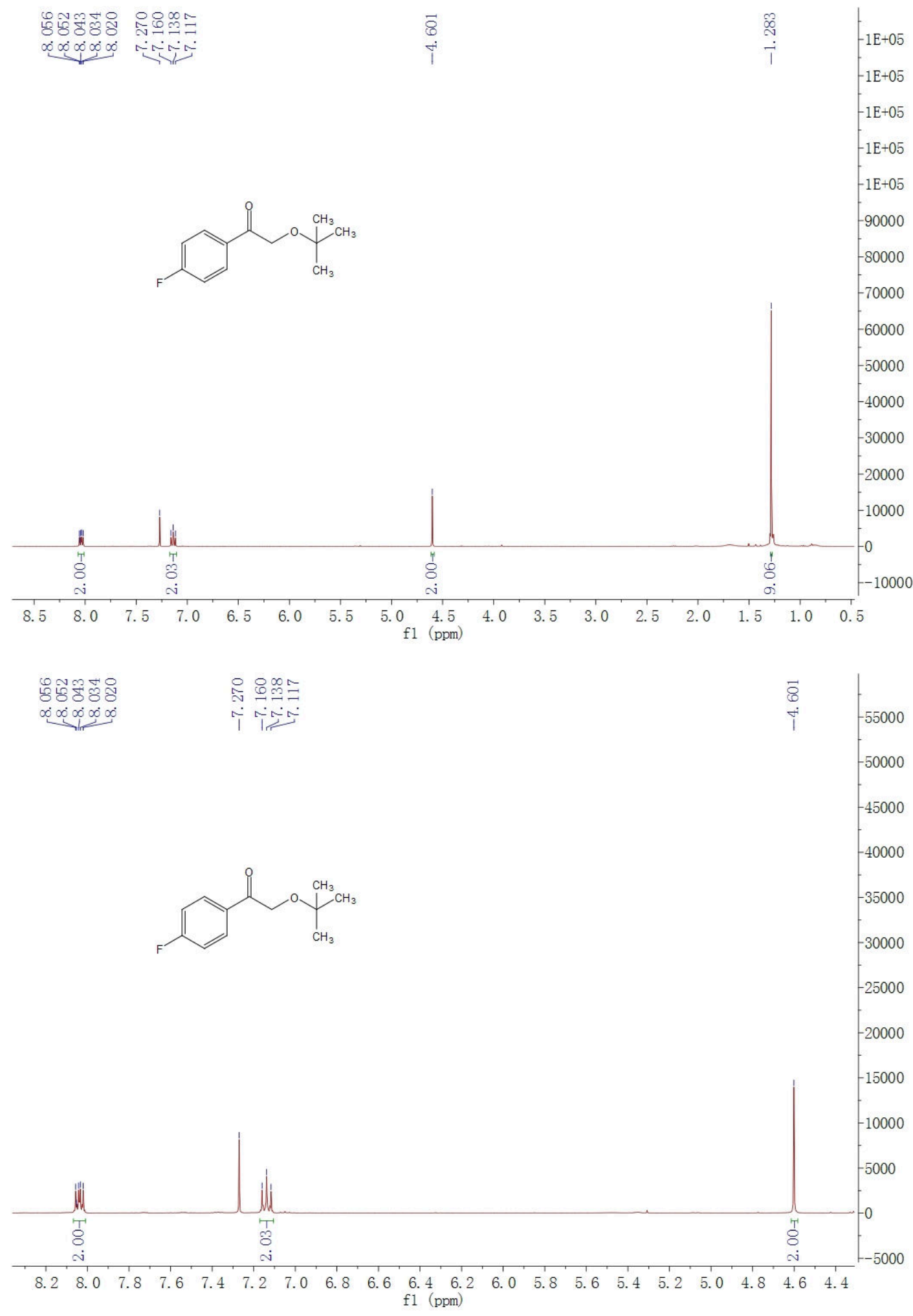




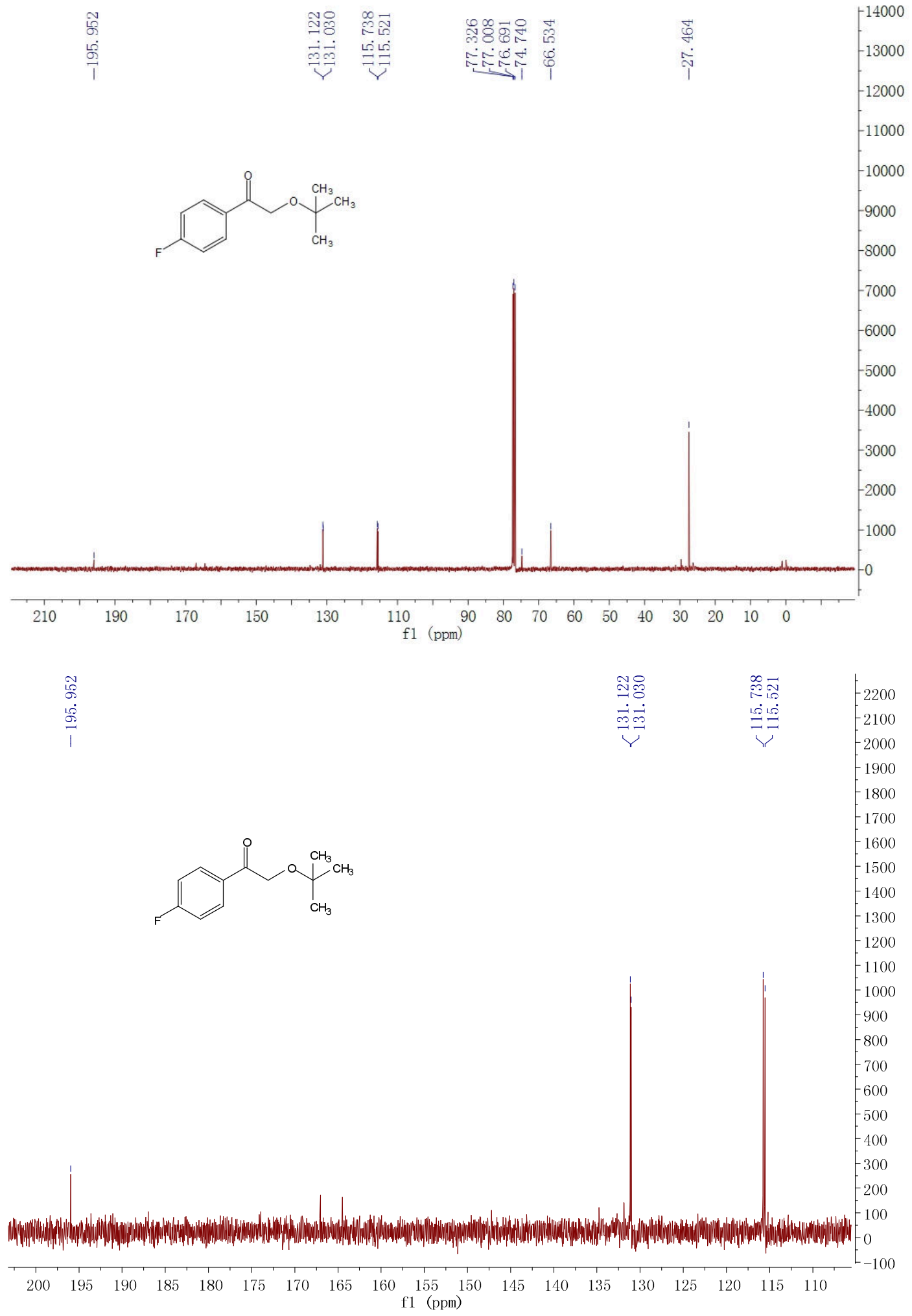


2-tert-butoxy-1-(4-chlorophenyl)ethanone (2i) ${ }^{2}$

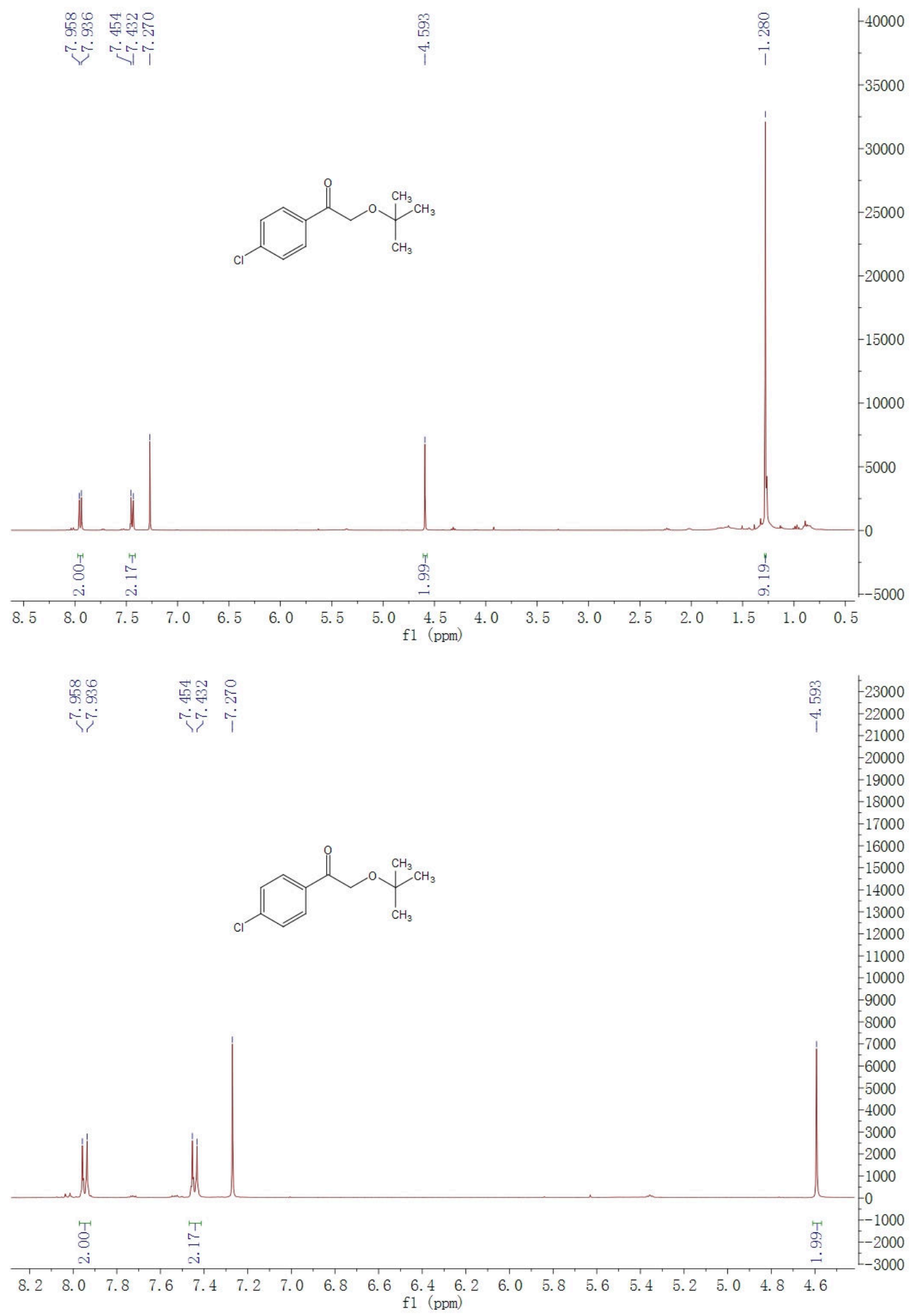




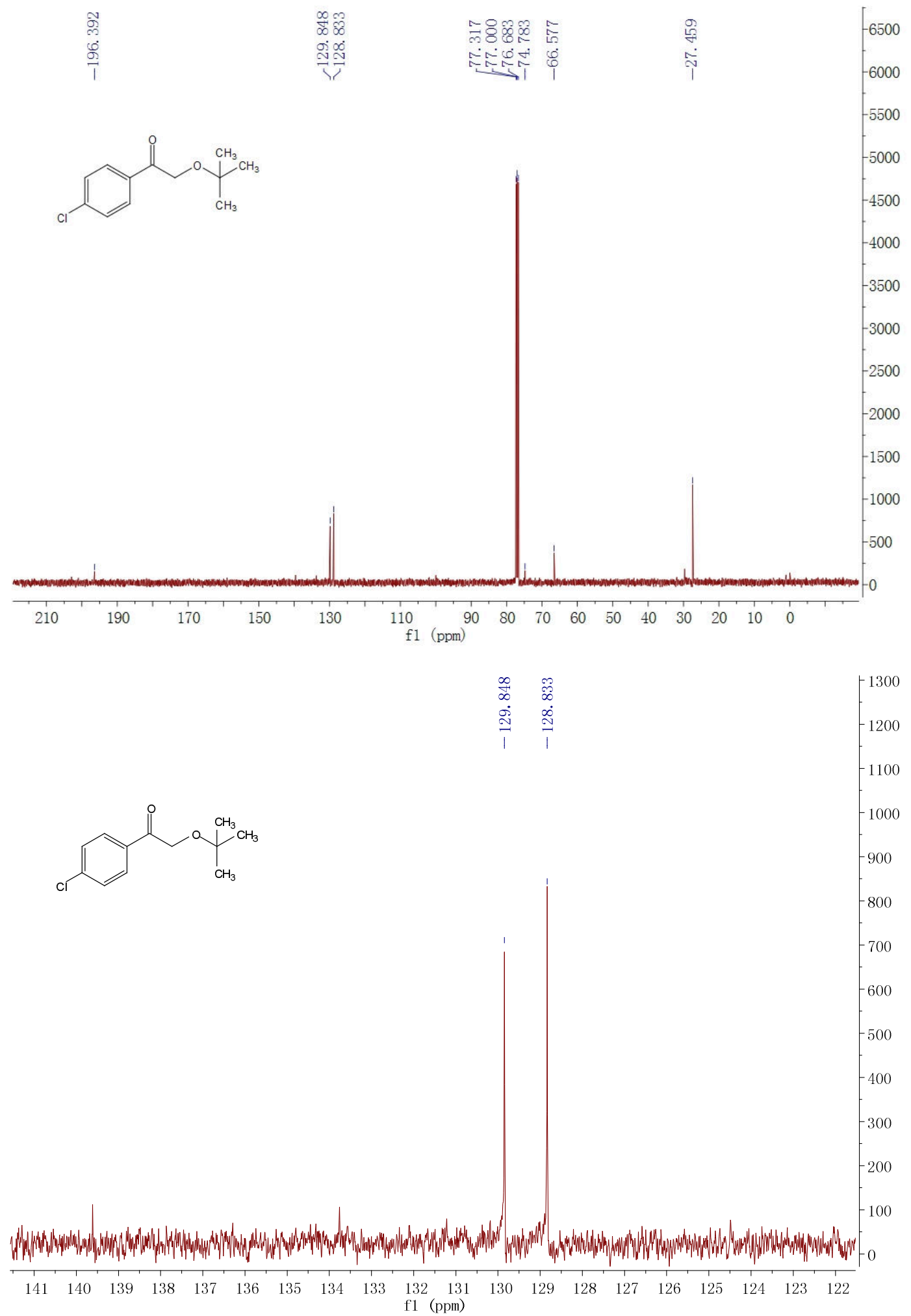


2-tert-butoxy-1-(4-(trifluoromethyl)phenyl)ethanone (2j)

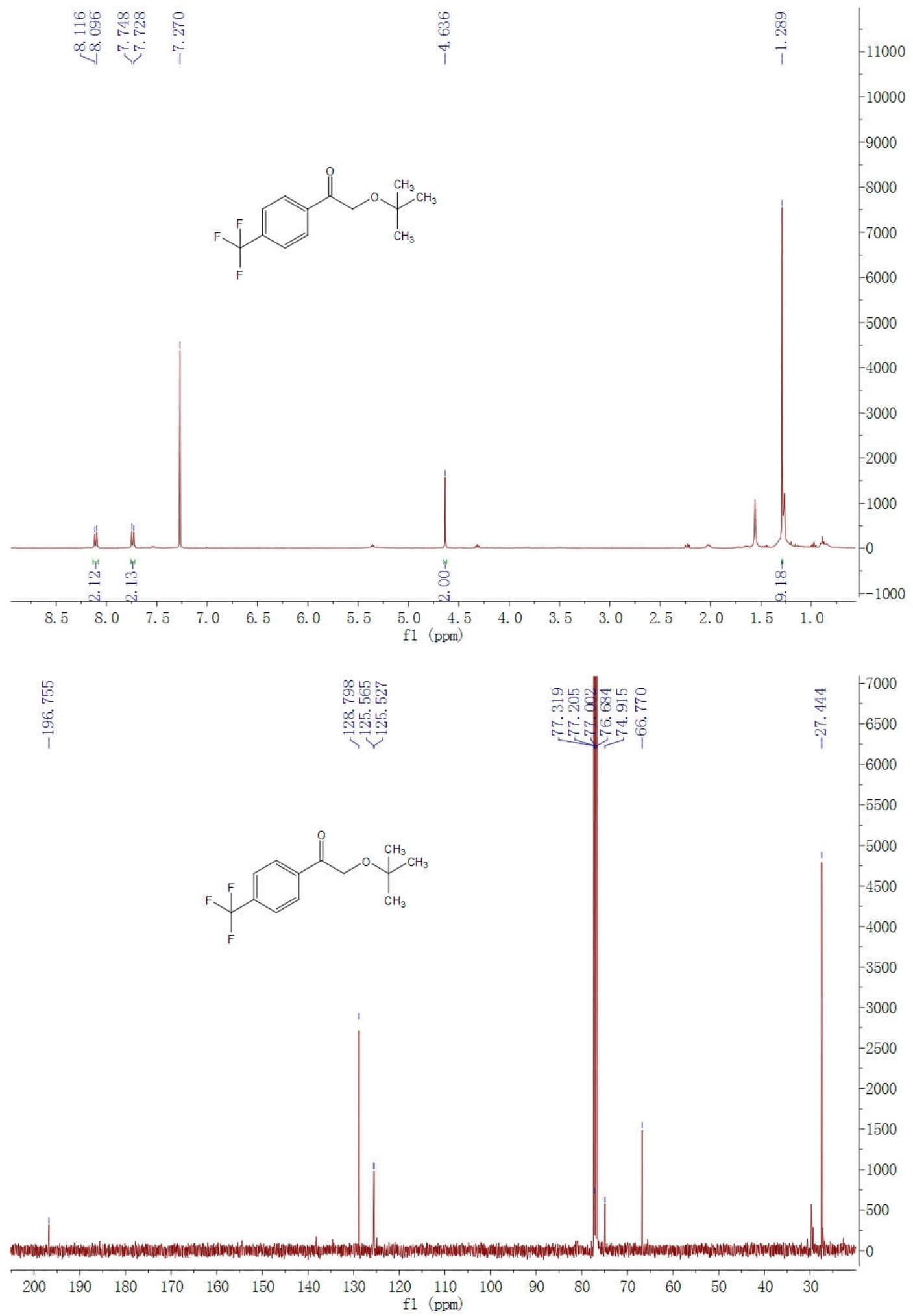




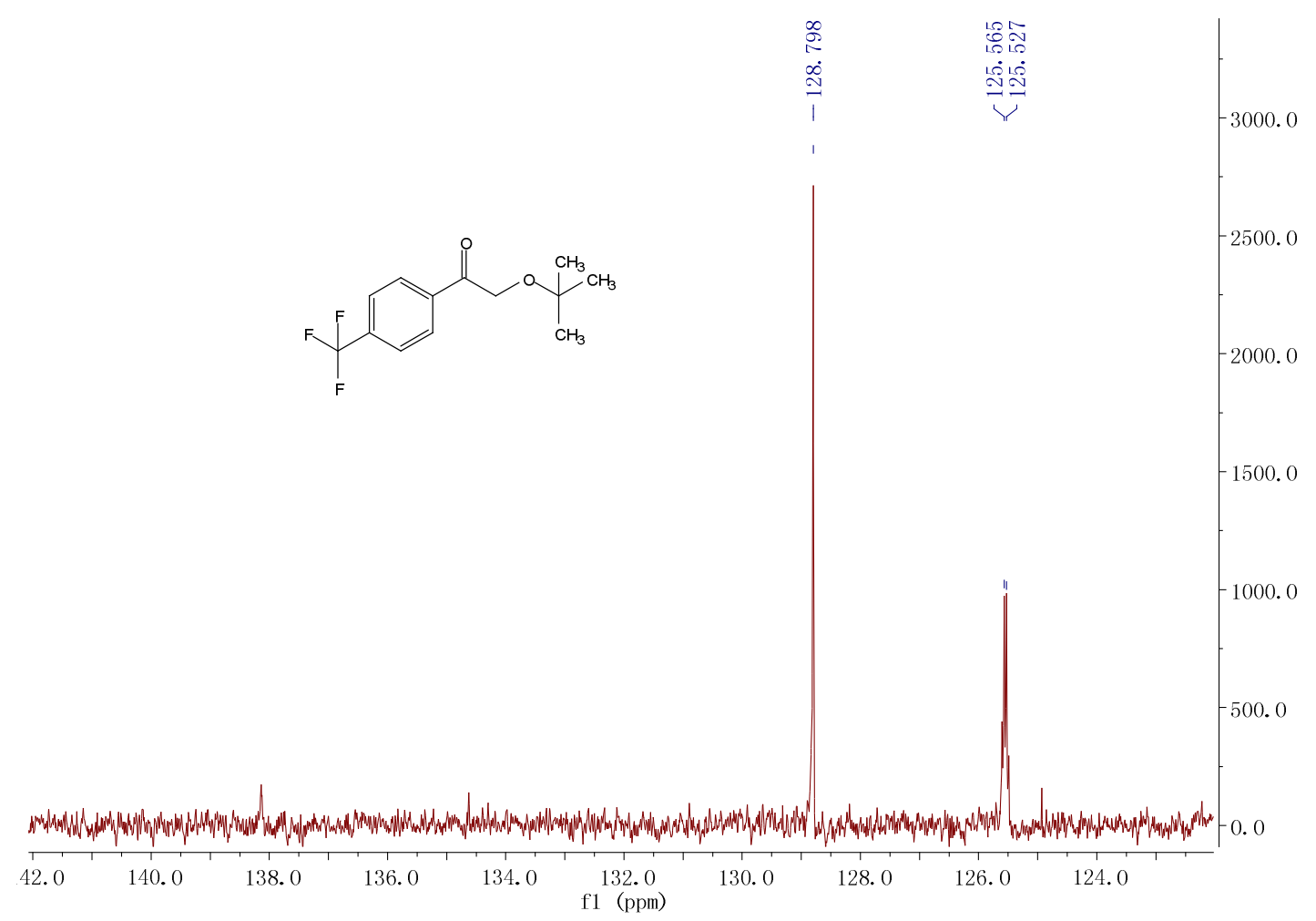

2-tert-butoxy-1-(4-nitrophenyl)ethanone (2k)

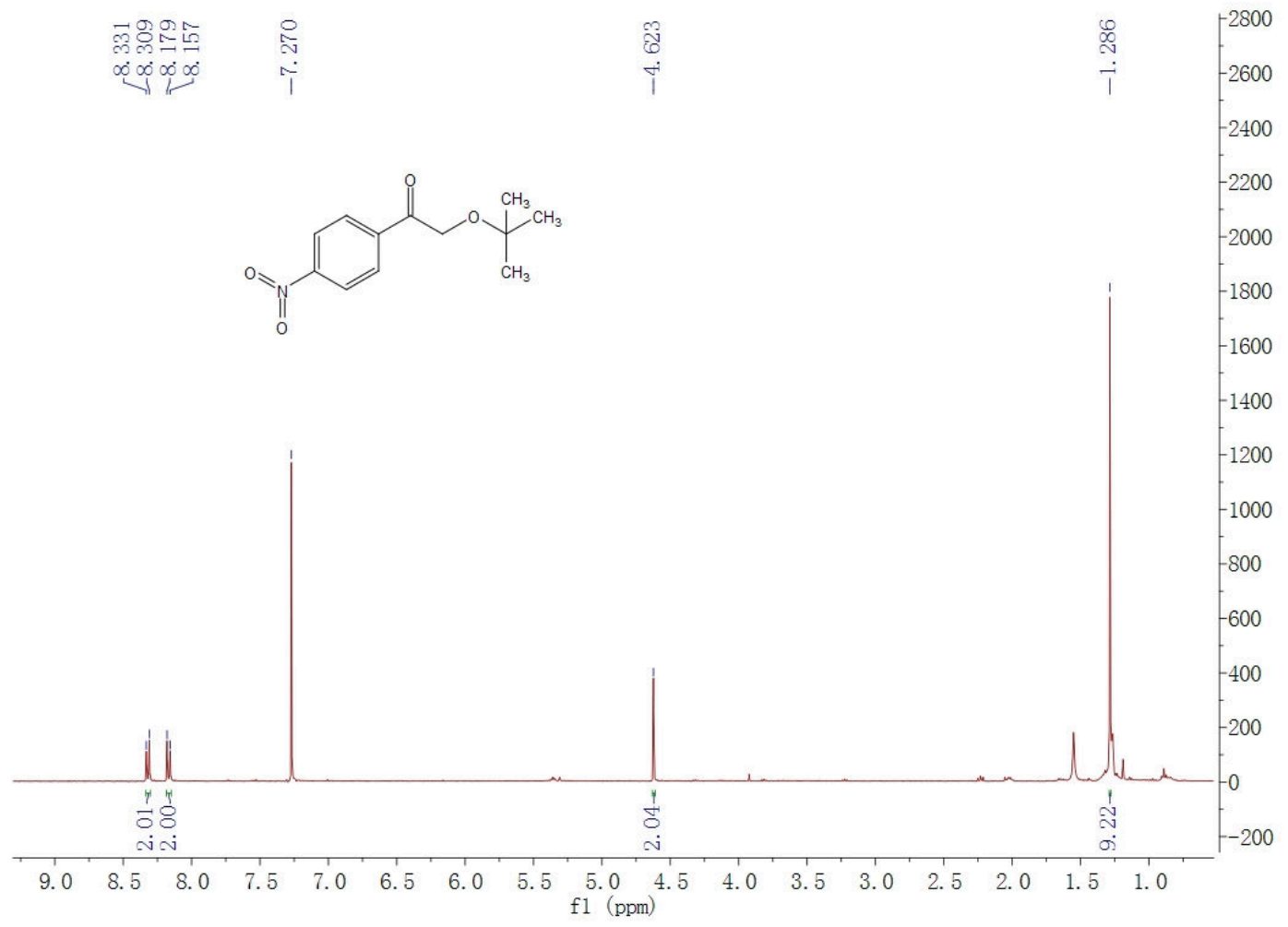




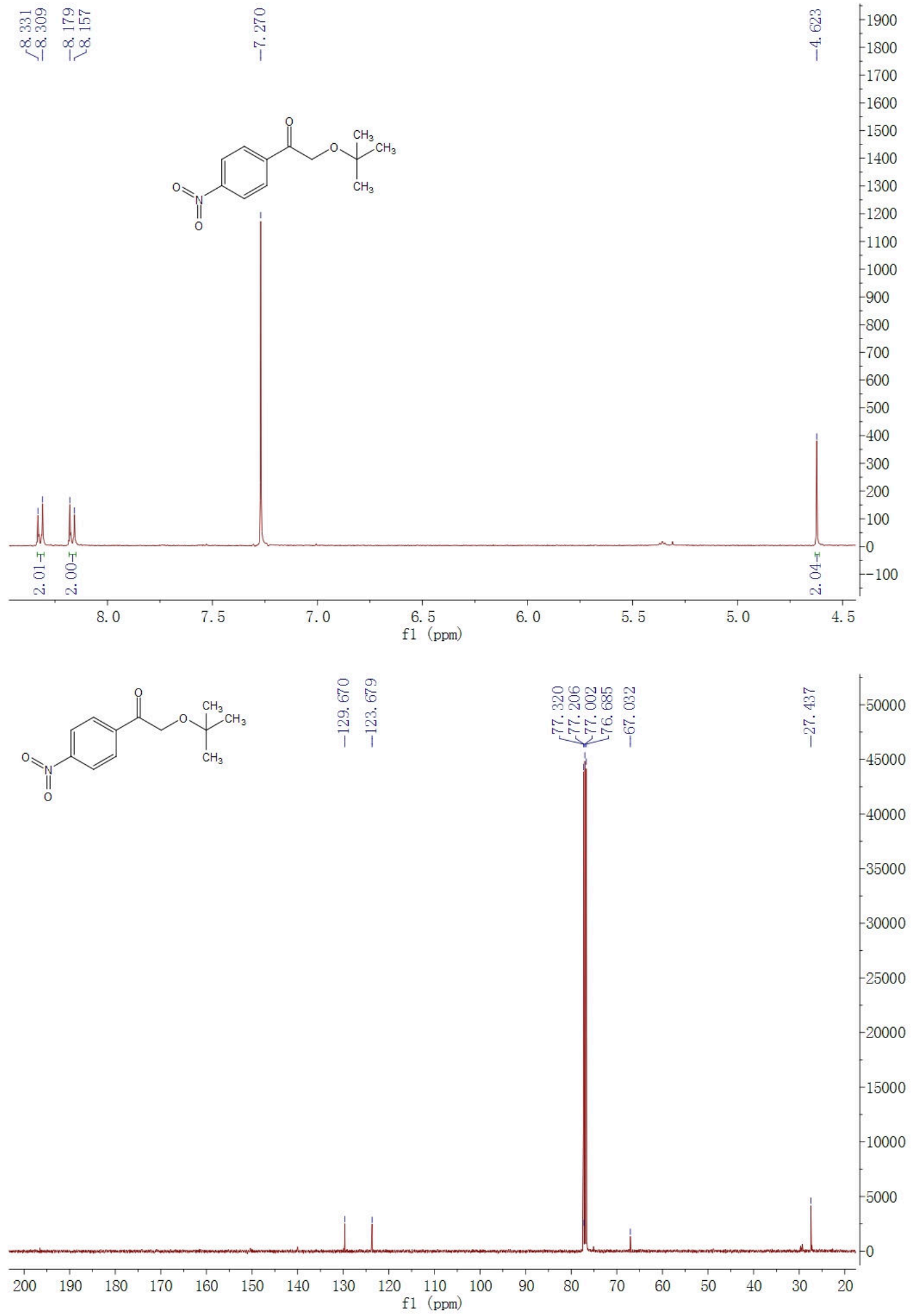



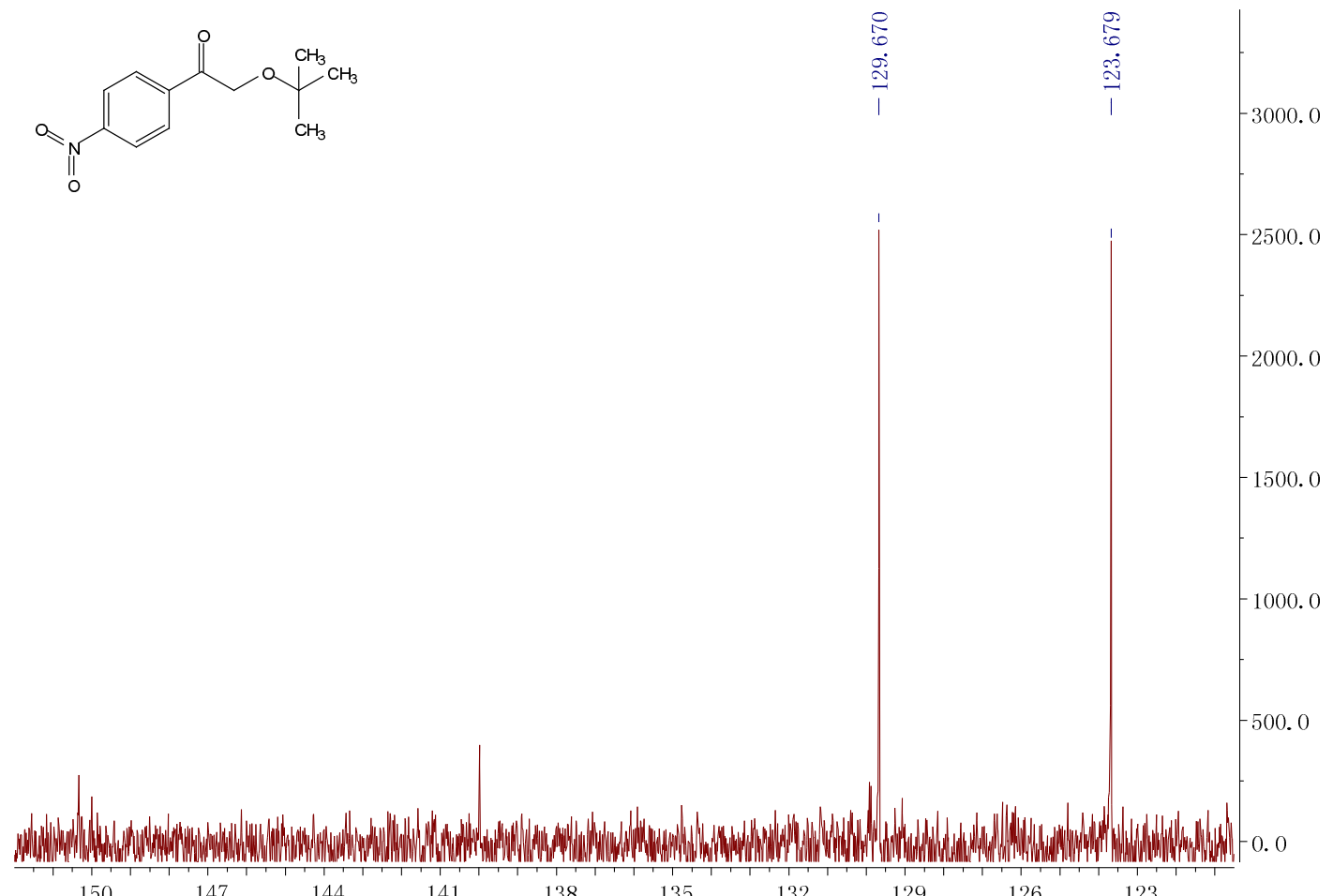

150

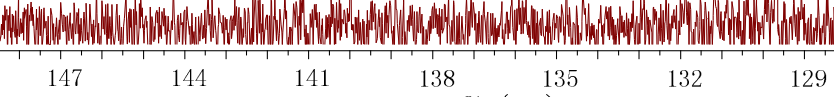

f1 (ppm)
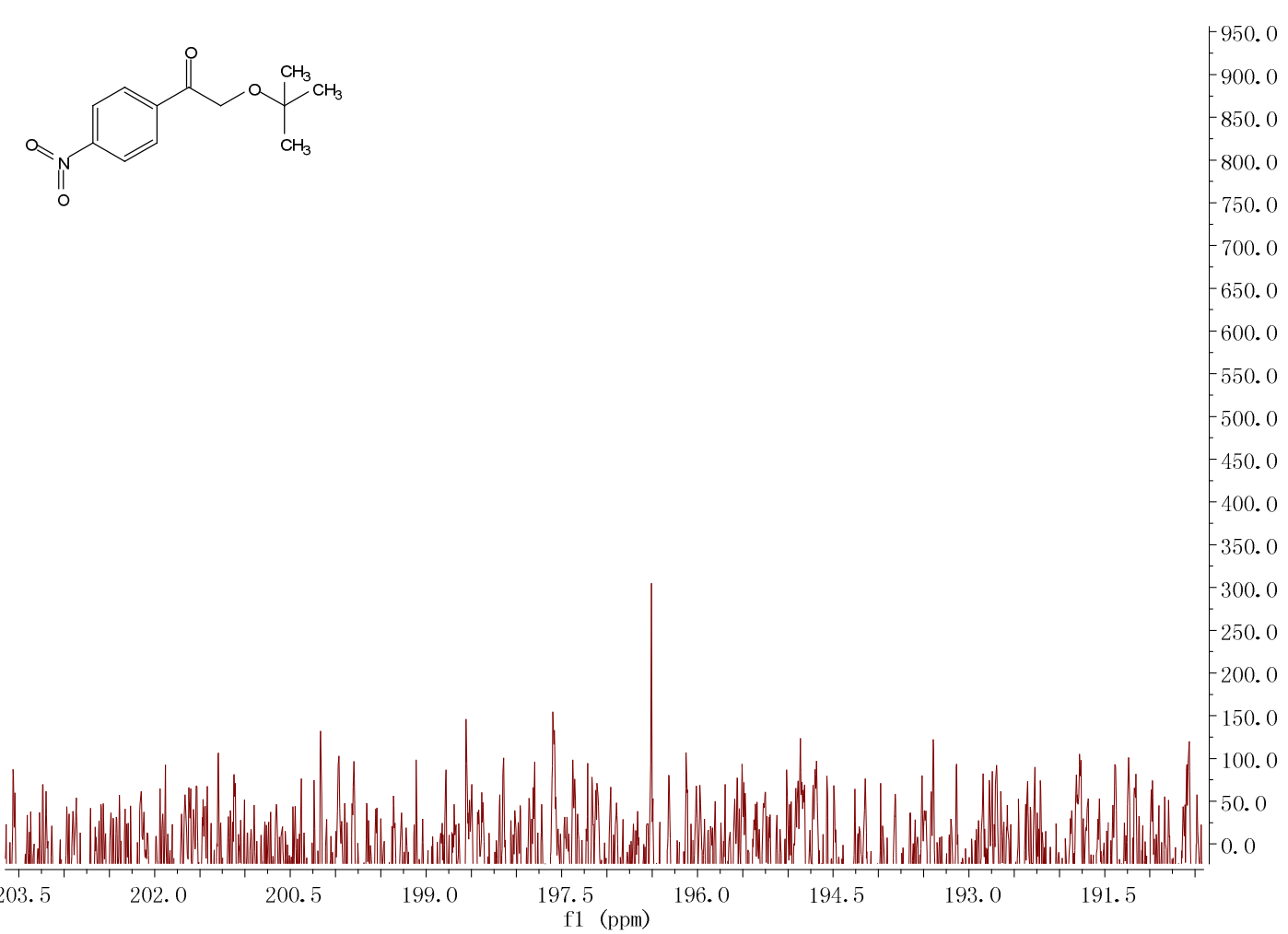
2-tert-butoxy-1-(2-fluorophenyl)ethanone (2l)

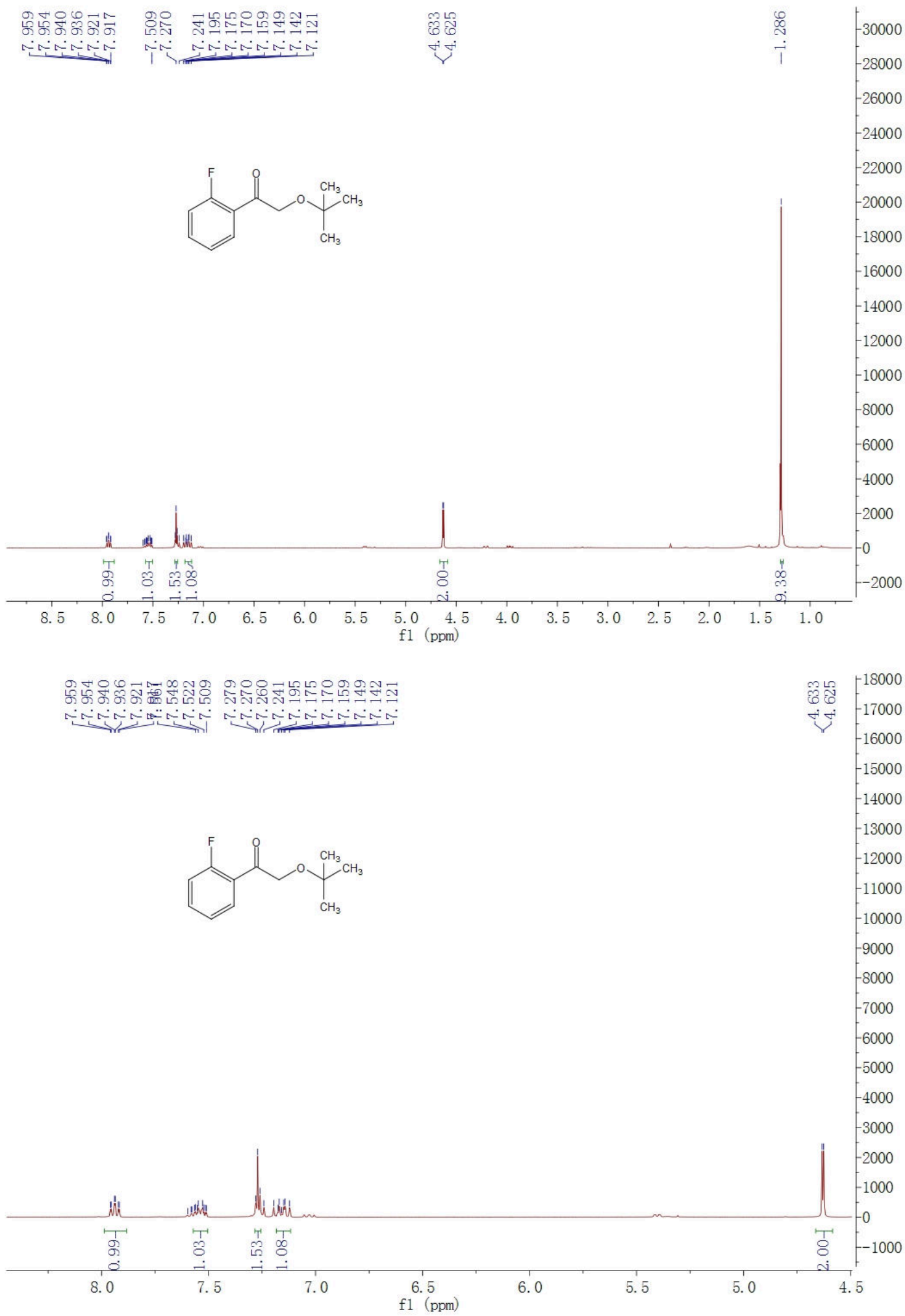



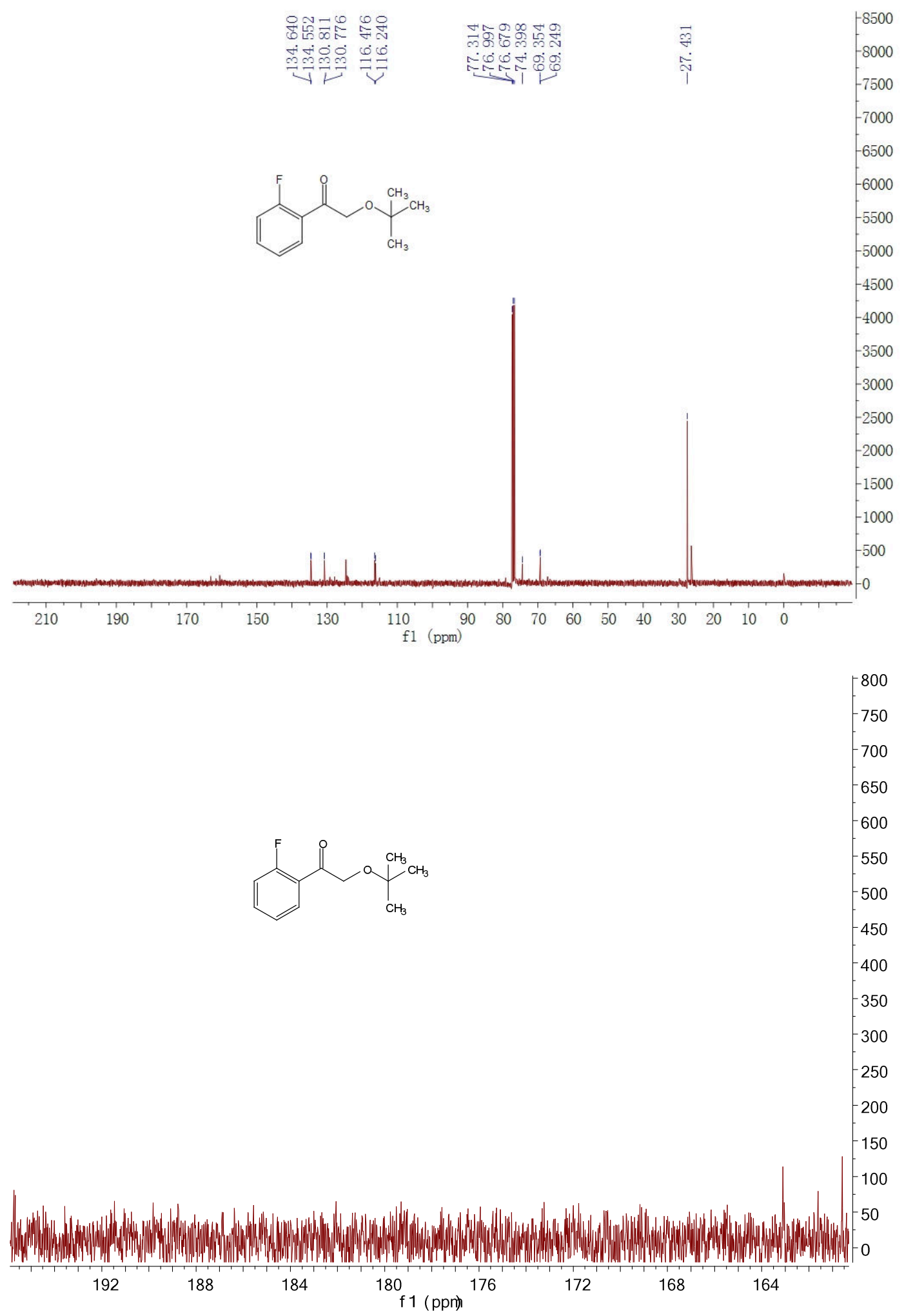
2-tert-butoxy-1-(3-methoxyphenyl)ethanone (2m)

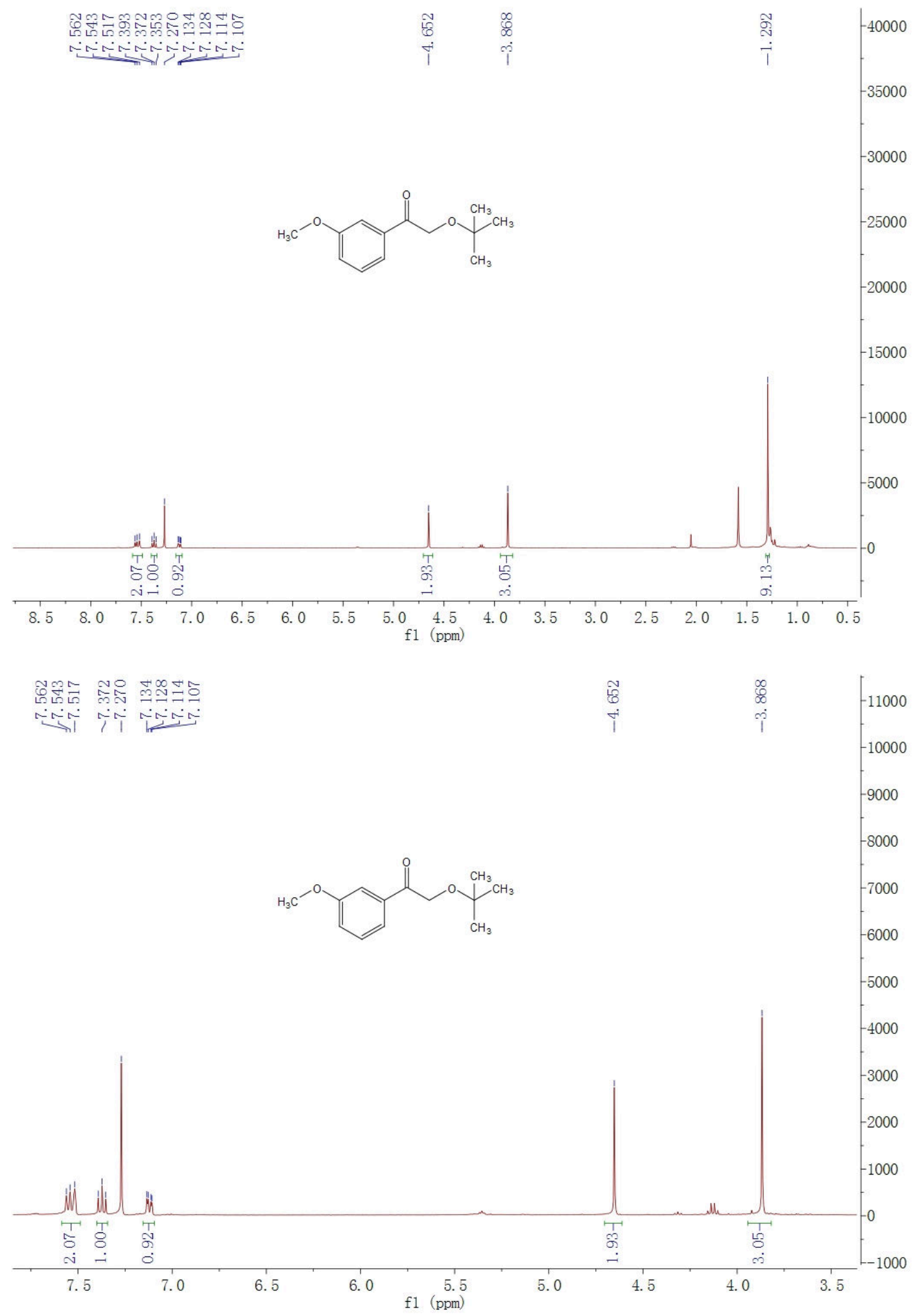



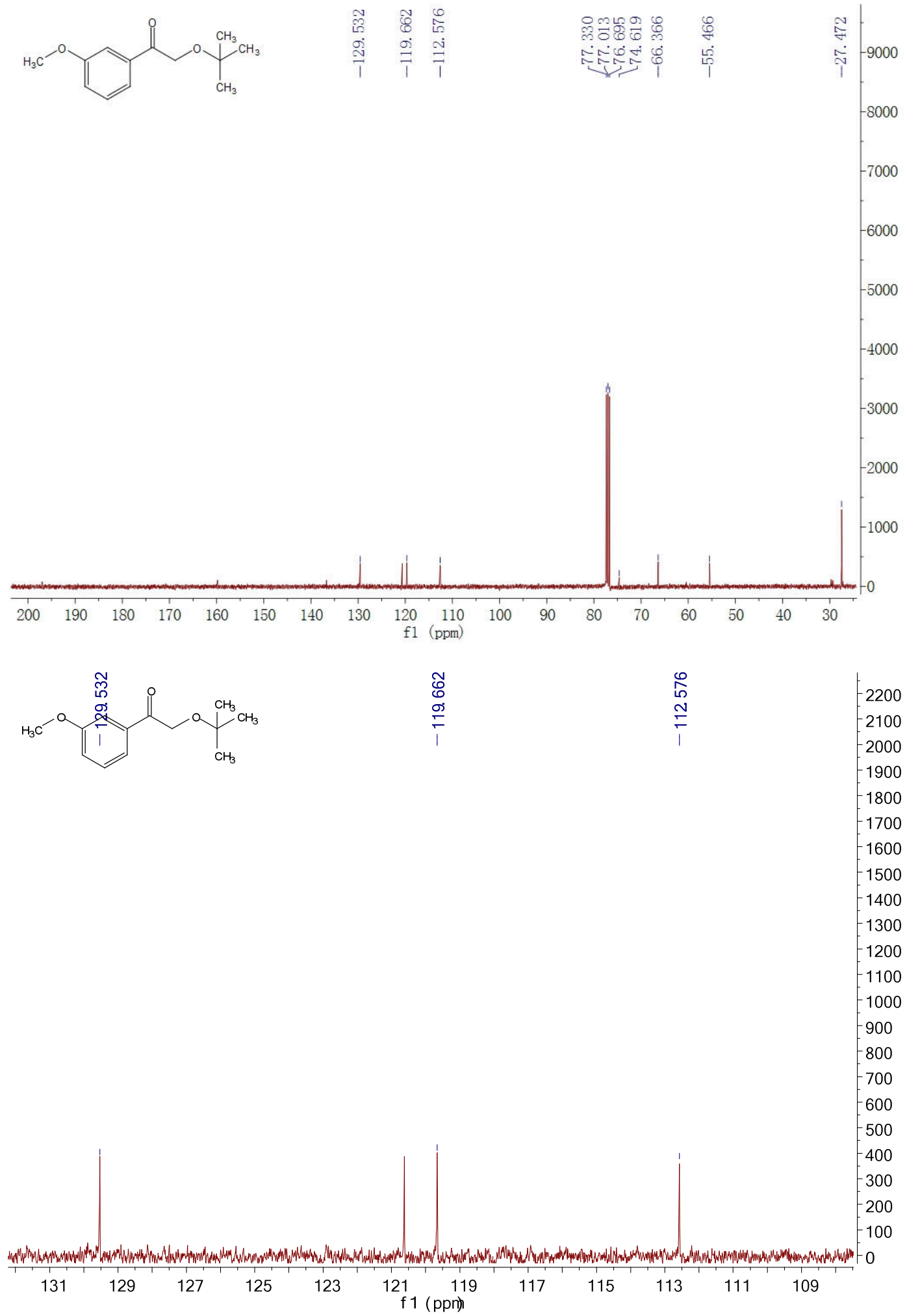
<smiles>COc1cccc(C(=O)COC(C)(C)C)c1</smiles>

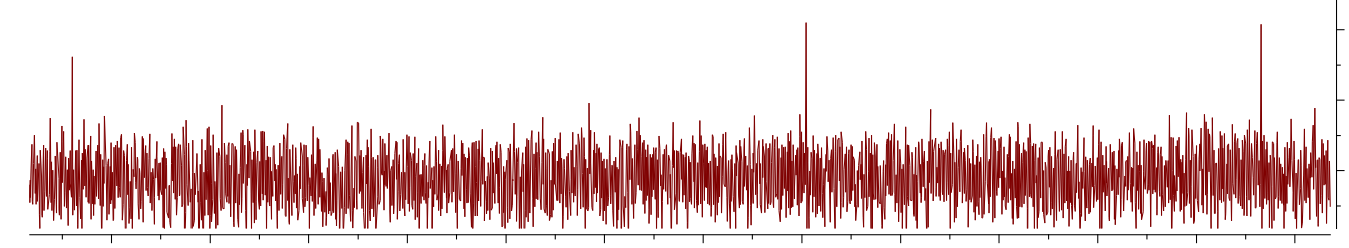

2-tert-butoxy-1-m-tolylethanone (2n)

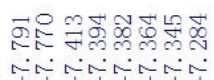

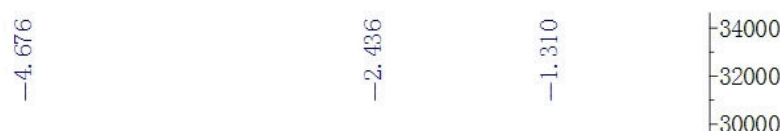

28000

$-26000$<smiles>Cc1cccc(C(=O)COC(C)(C)C)c1</smiles>

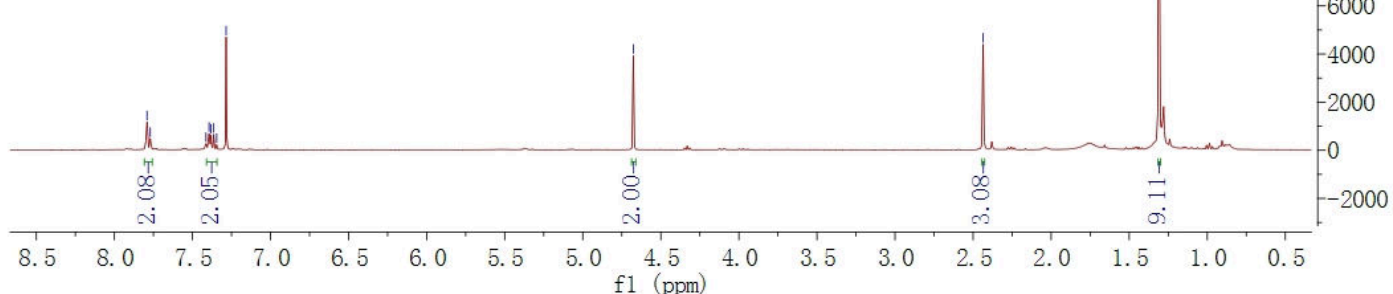



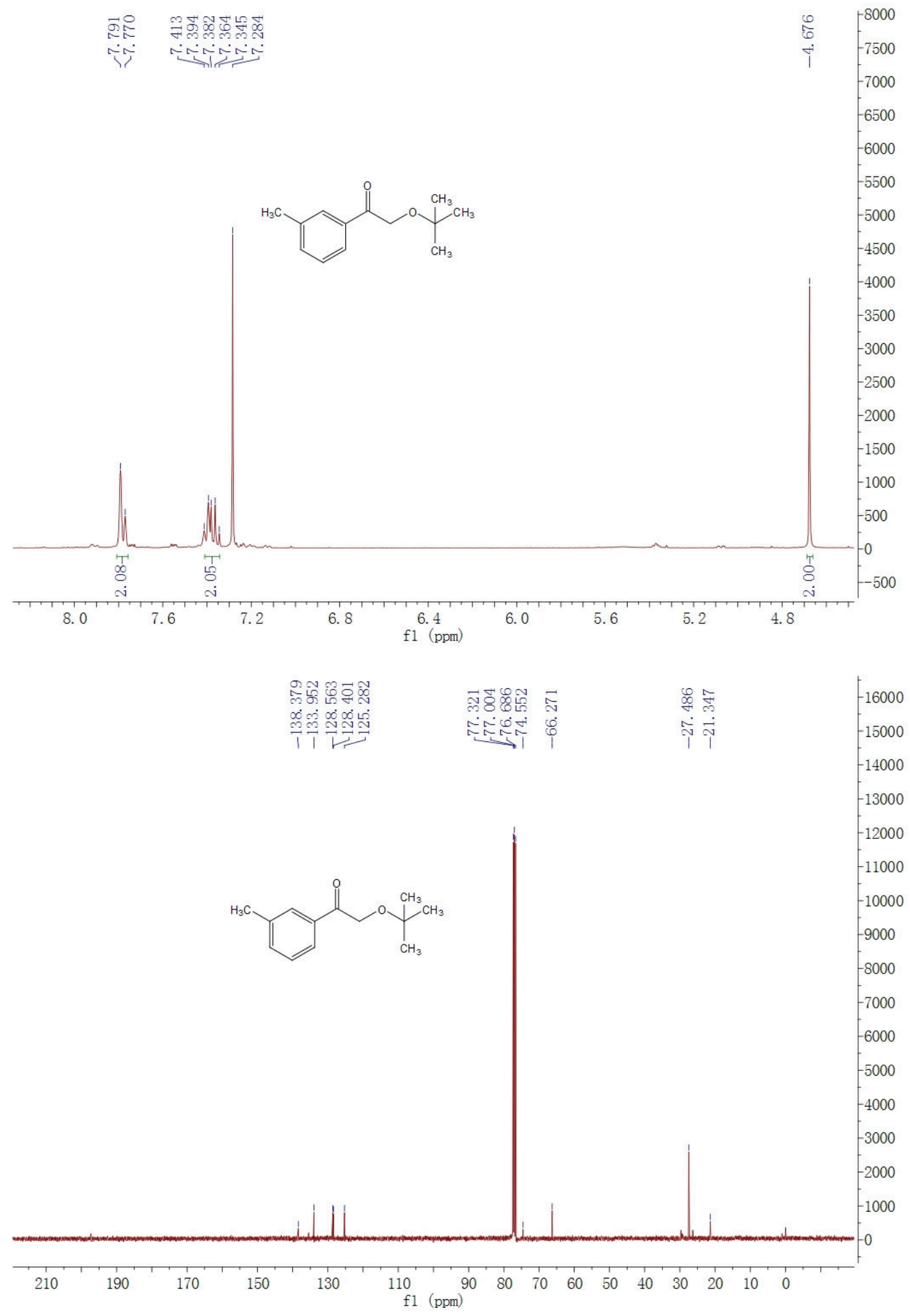

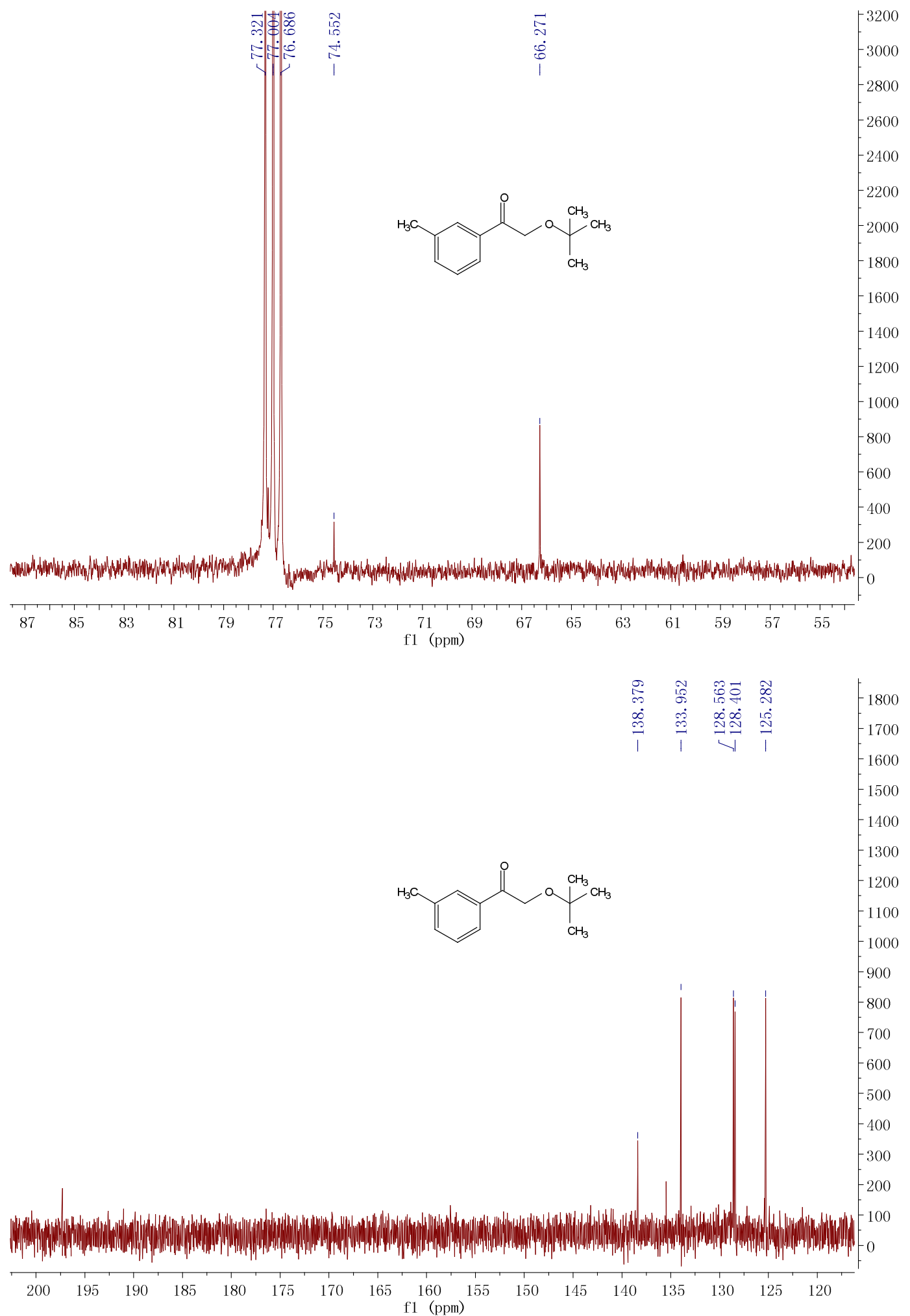
2-tert-butoxy-1-(3-fluorophenyl)ethanone (20)

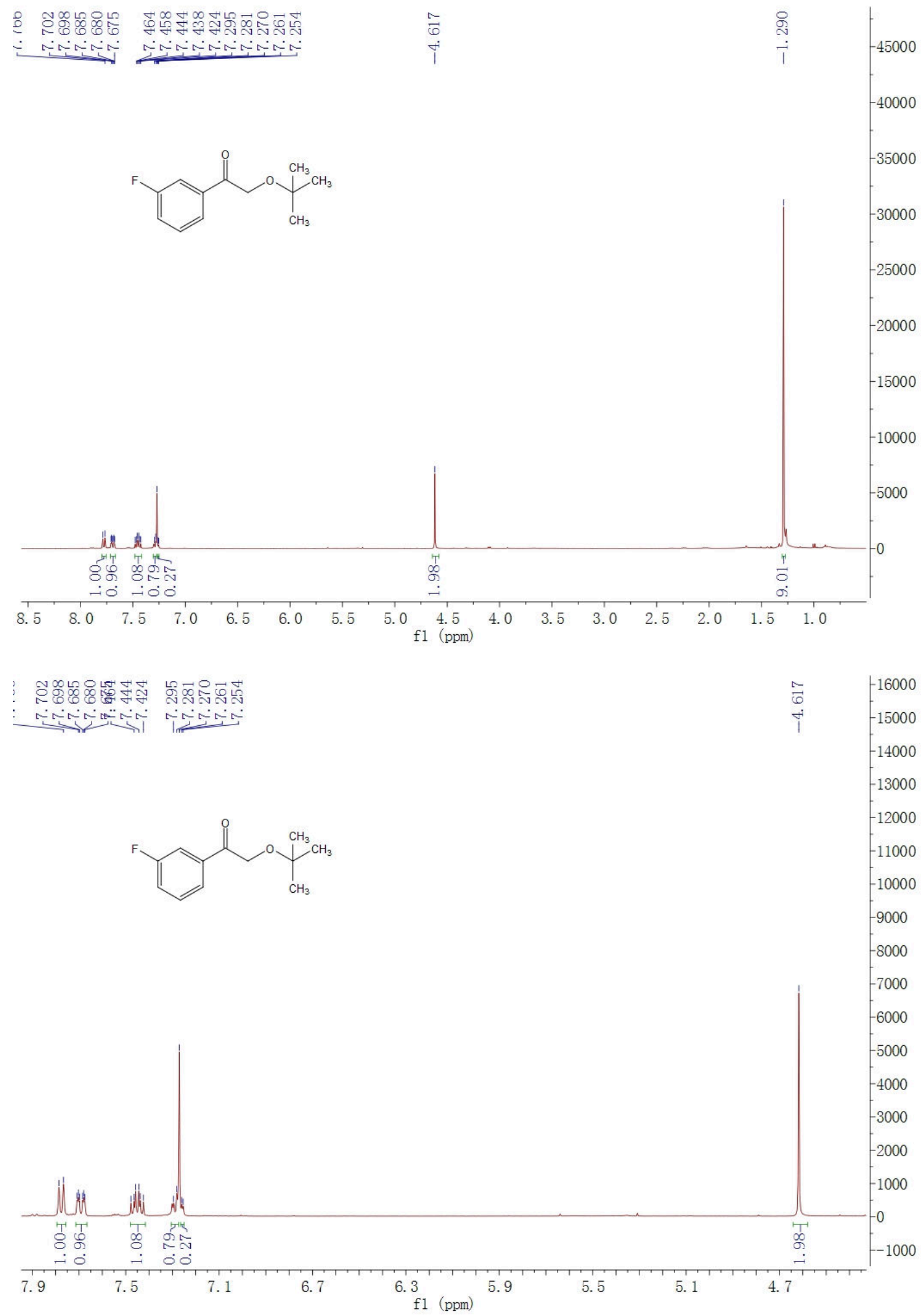




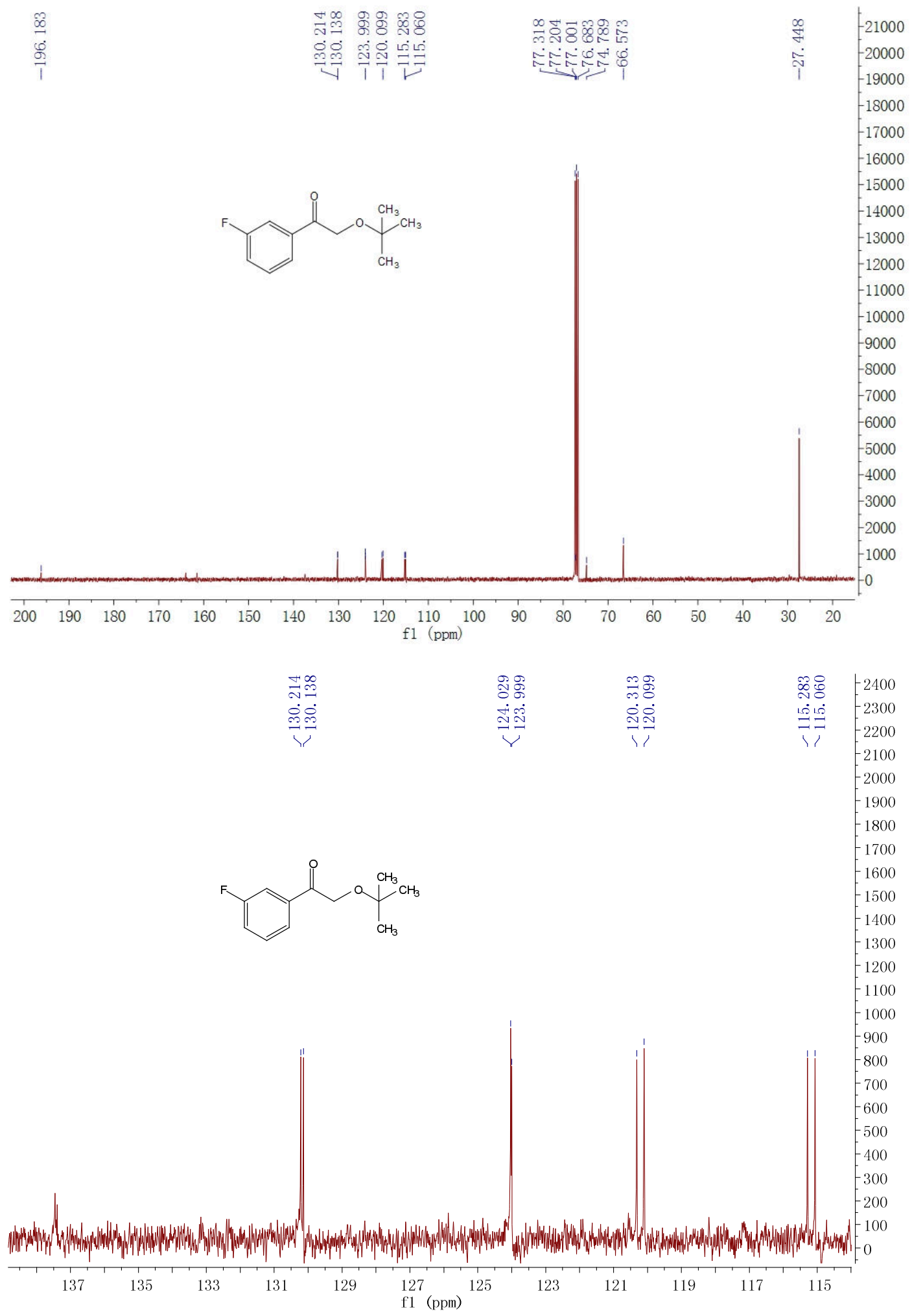




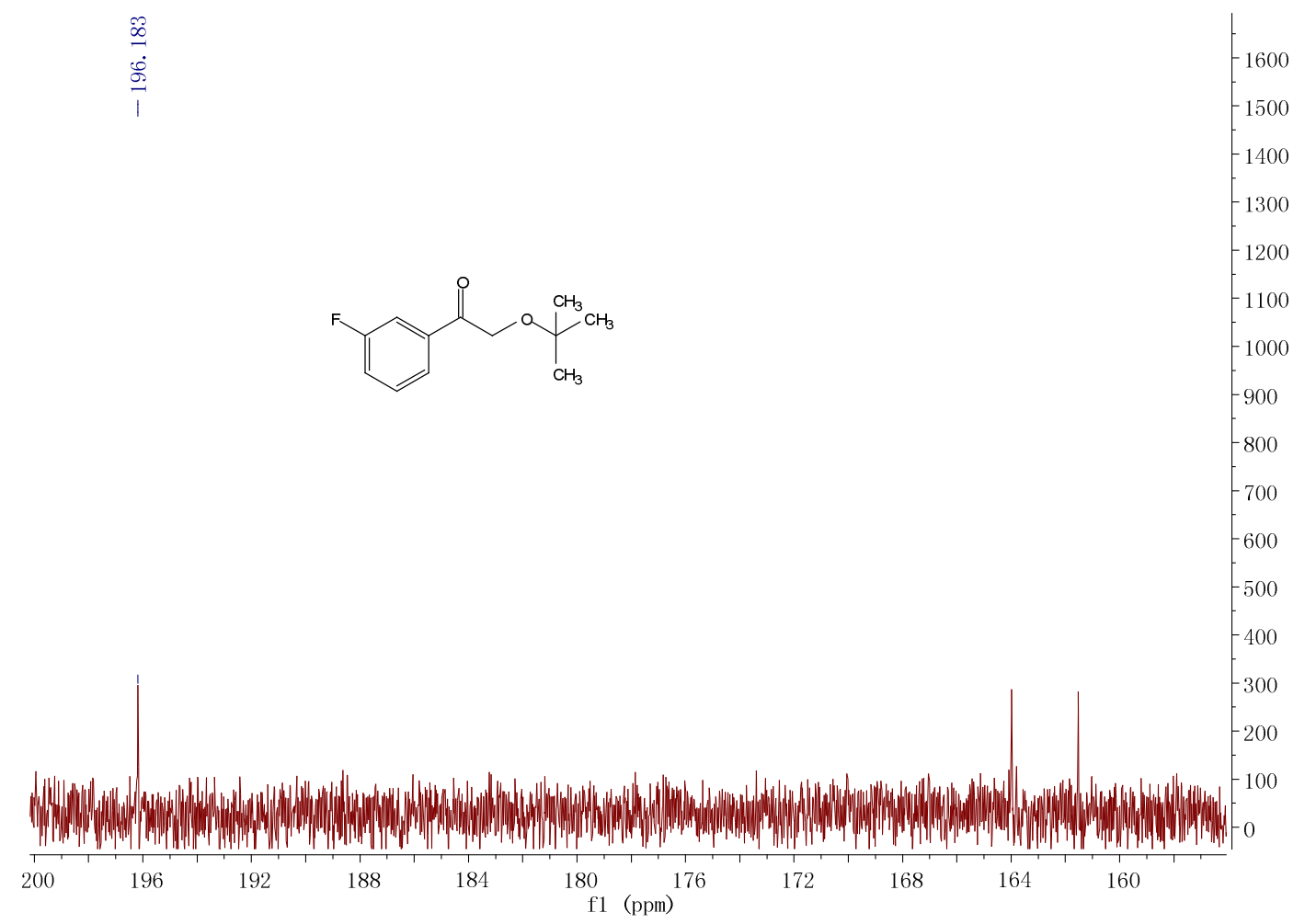

2-tert-butoxy-1-(3-chlorophenyl)ethanone (2p)

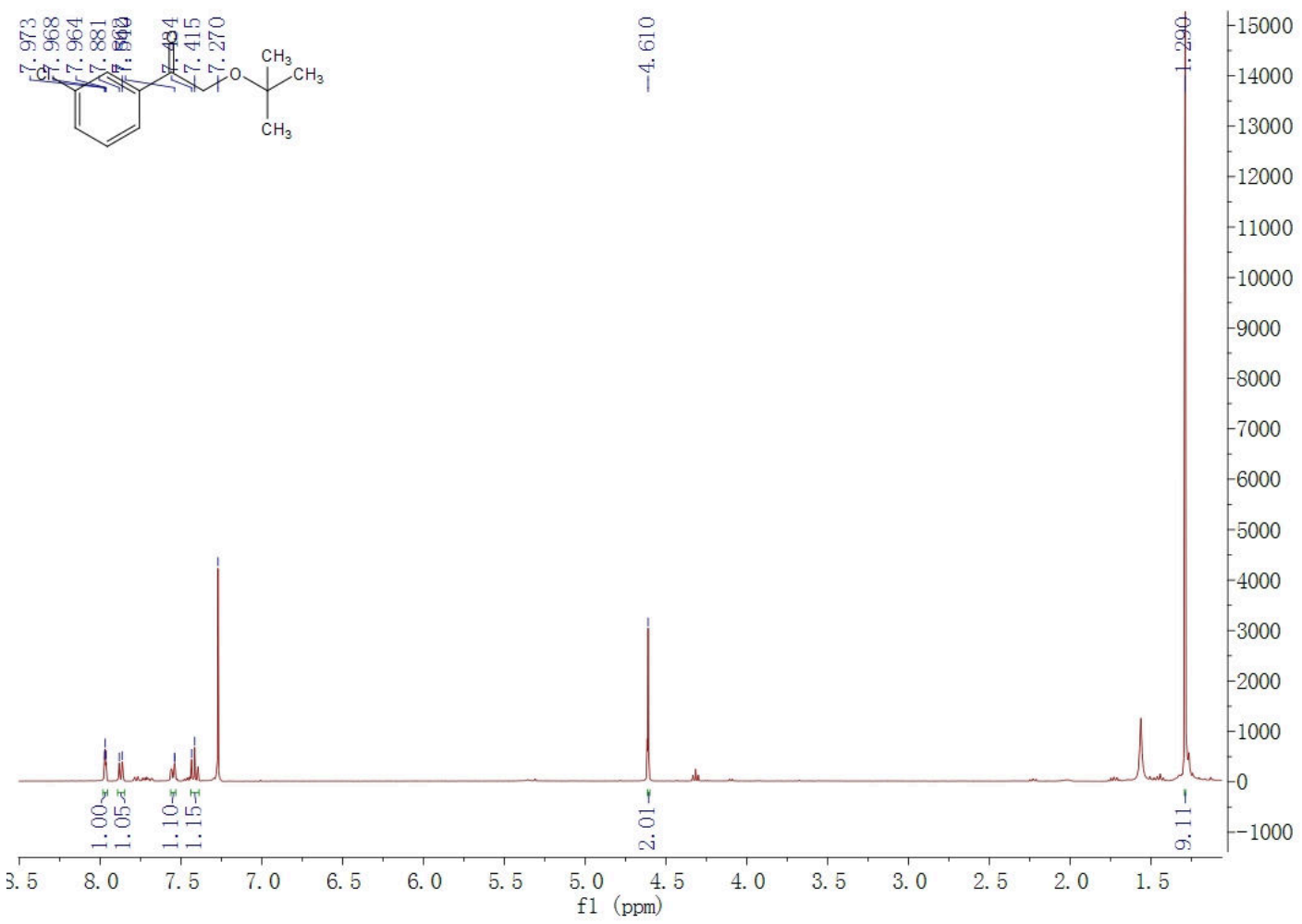




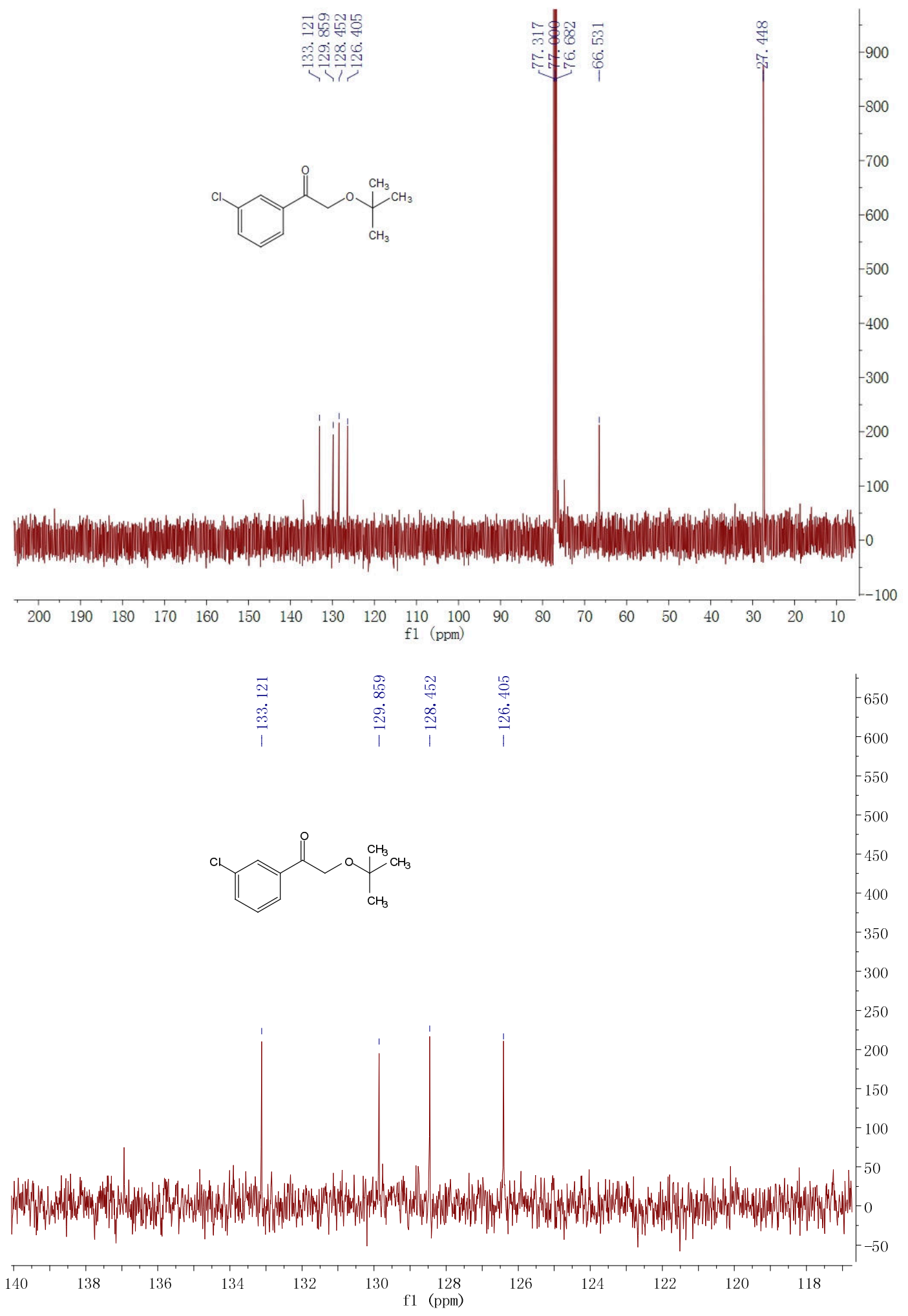


2-tert-butoxy-1-(naphthalen-3-yl)ethanone (2q)

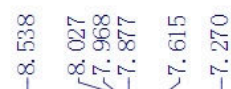

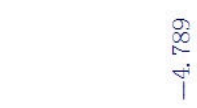

$\stackrel{\infty}{i}$<smiles>CC(C)(C)OCC(=O)c1ccc2ccccc2c1</smiles>

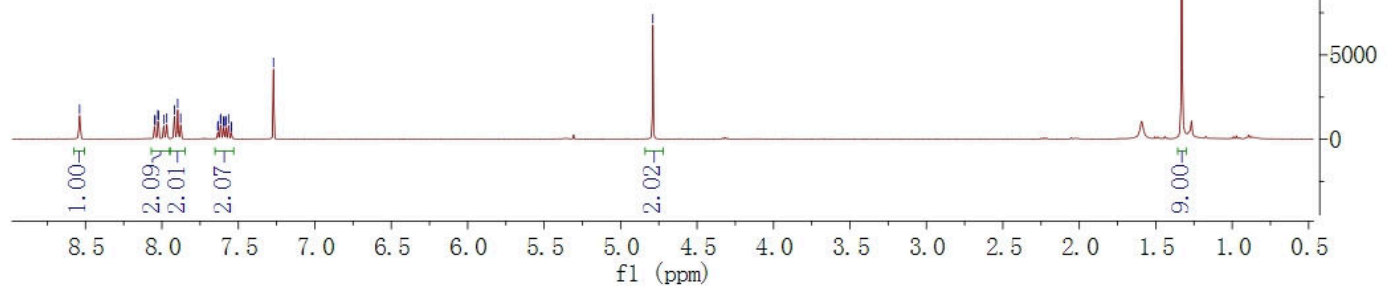

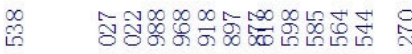

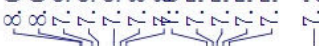<smiles>CC(C)(C)OCC(=O)c1ccc2ccccc2c1</smiles>

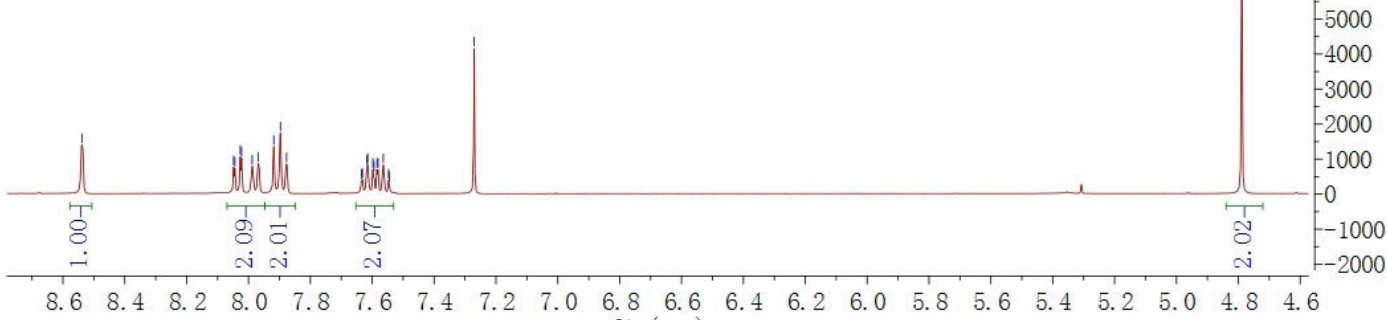

f1 (ppm) 


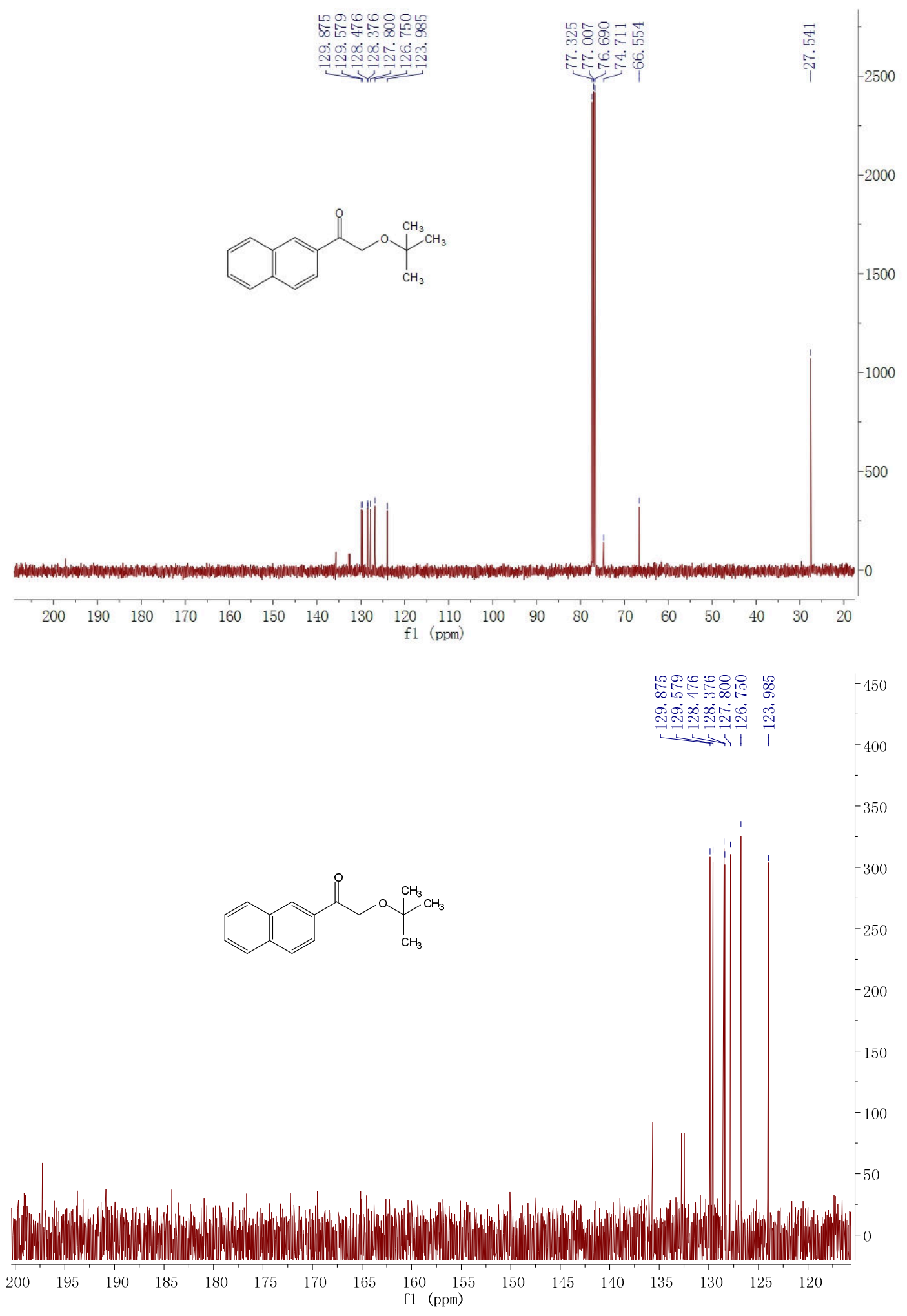


2-tert-butoxy-1-(thiophen-2-yl)ethanone (2u)

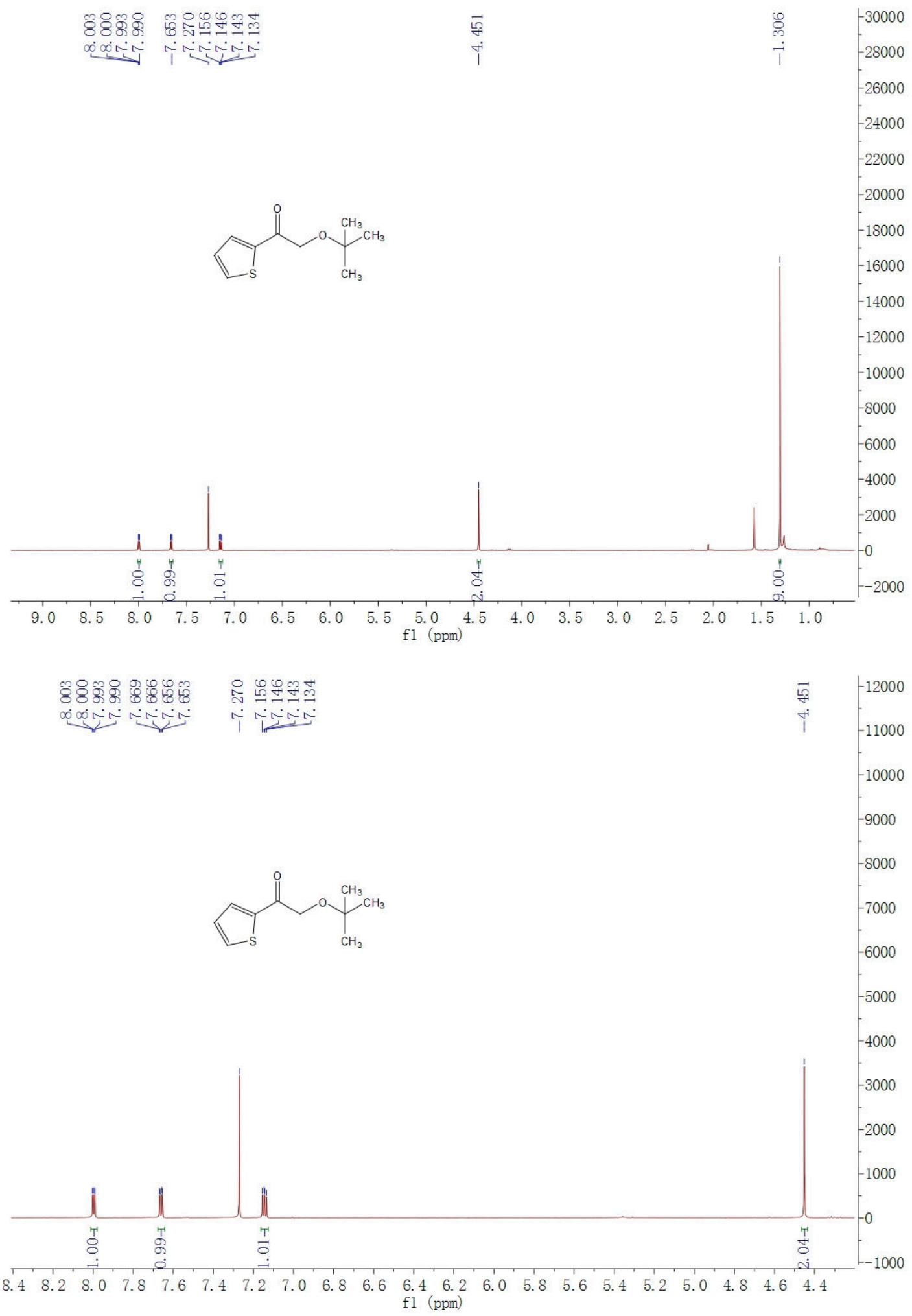



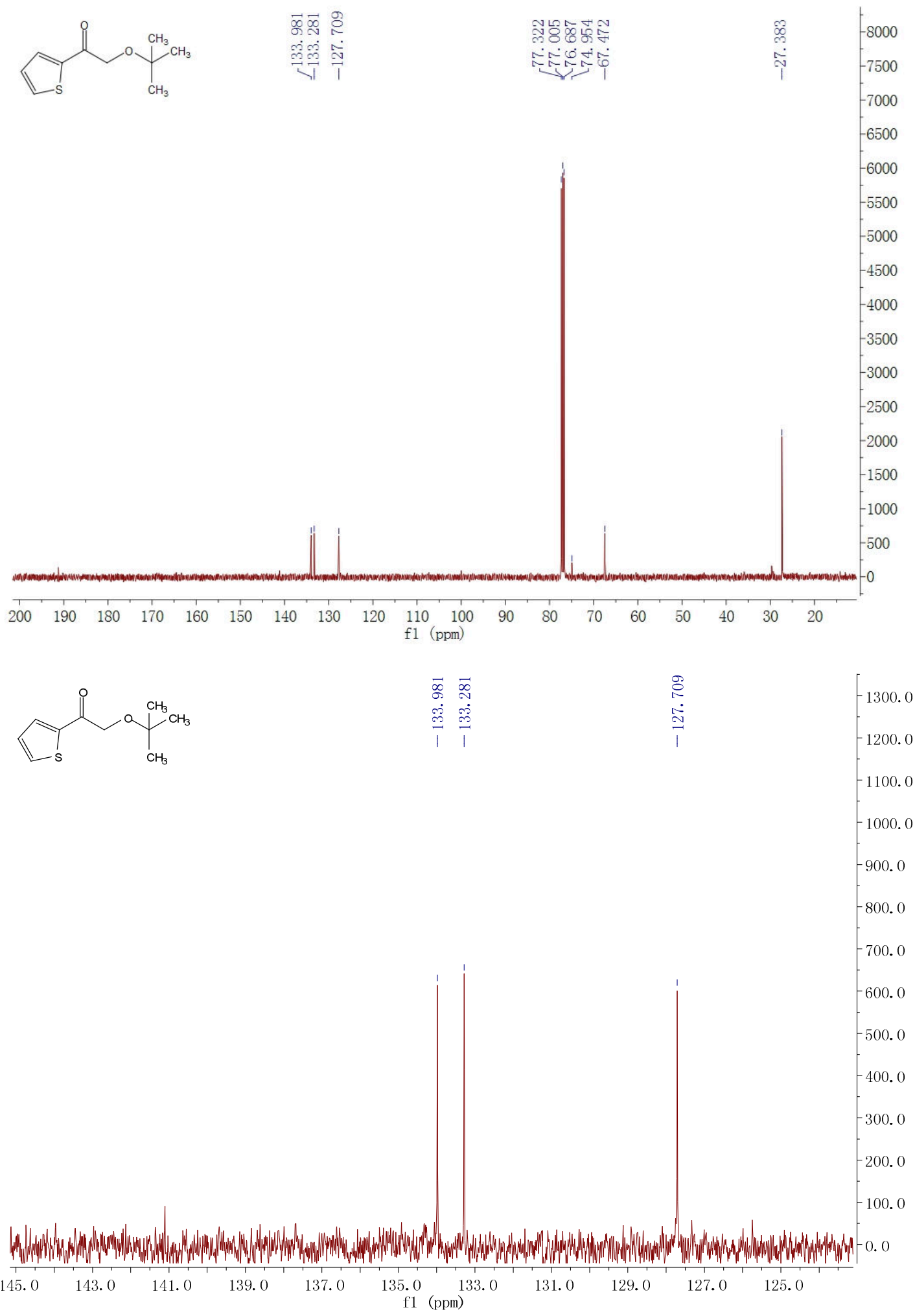

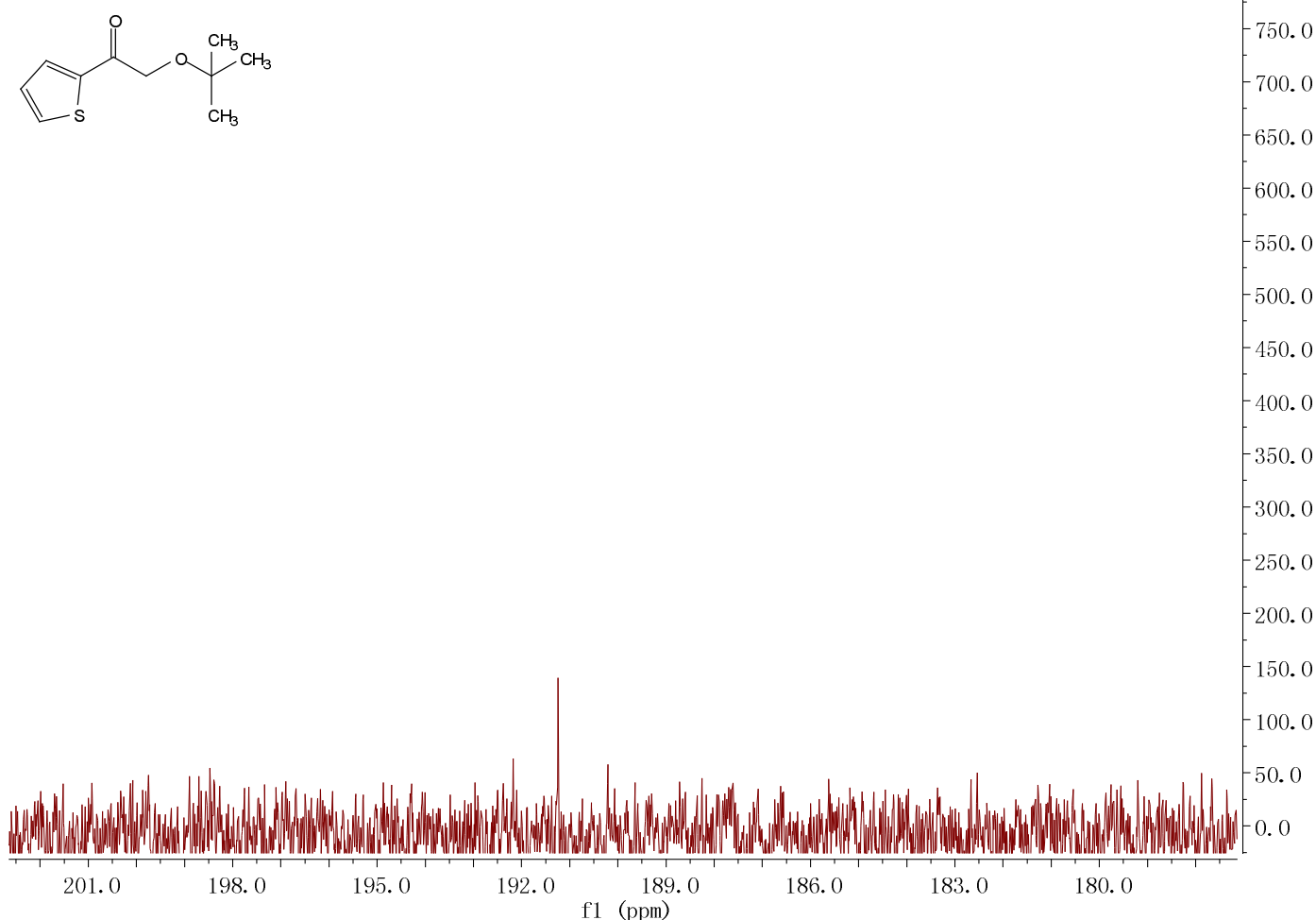

1-((E)-3-(tert-butylperoxy)prop-1-enyl)benzene (5a)

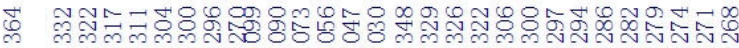

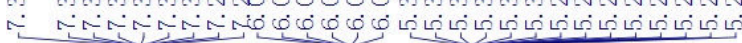<smiles>CC(C)(C)OOC/C=C/c1ccccc1</smiles>

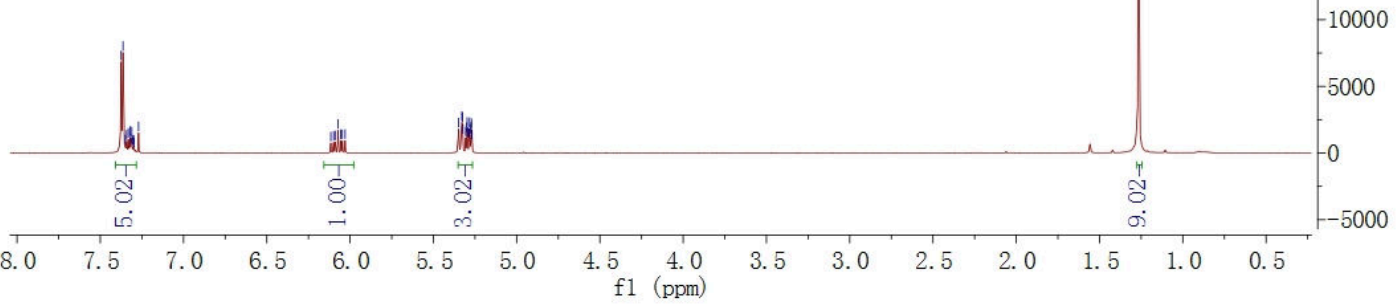




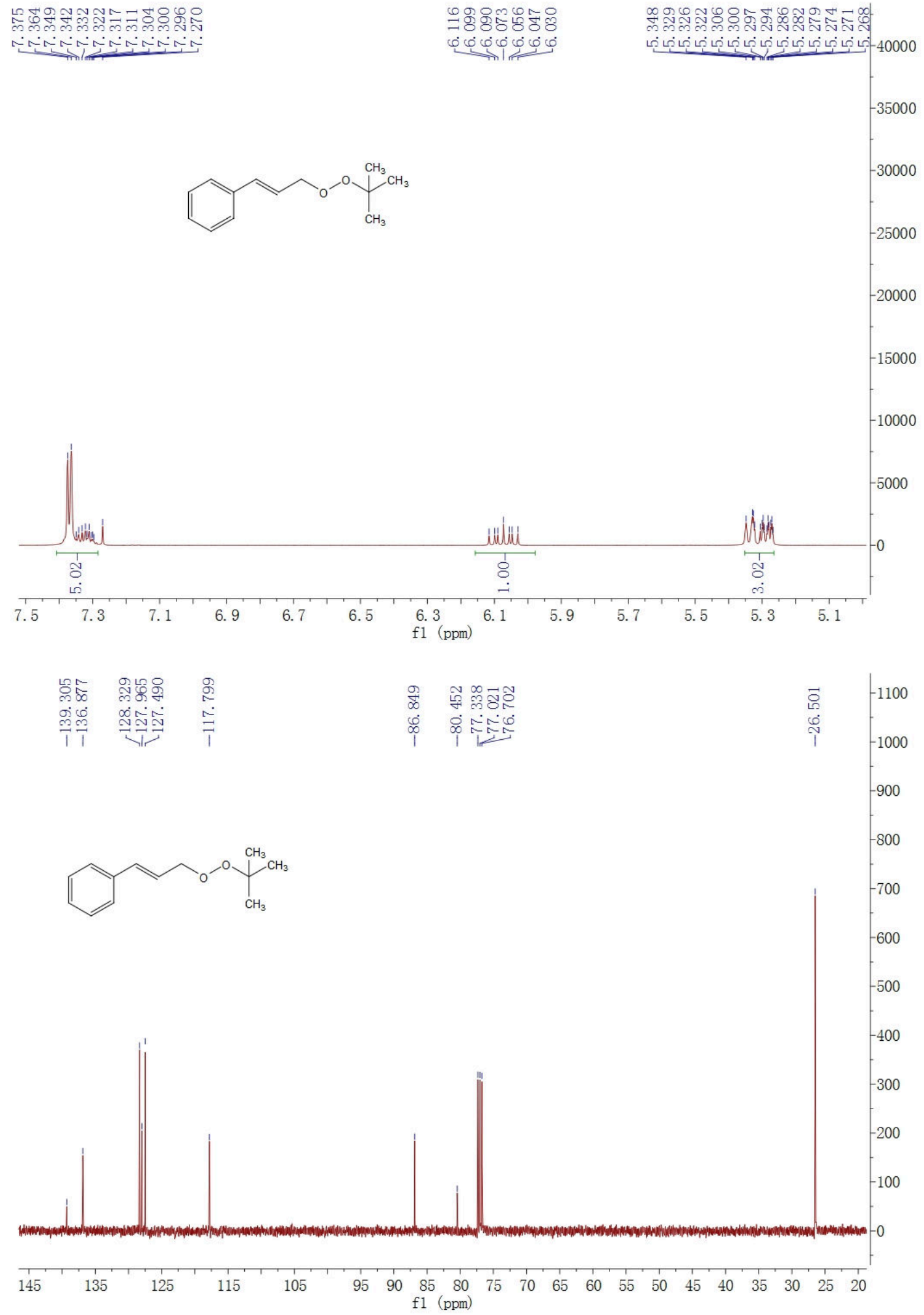




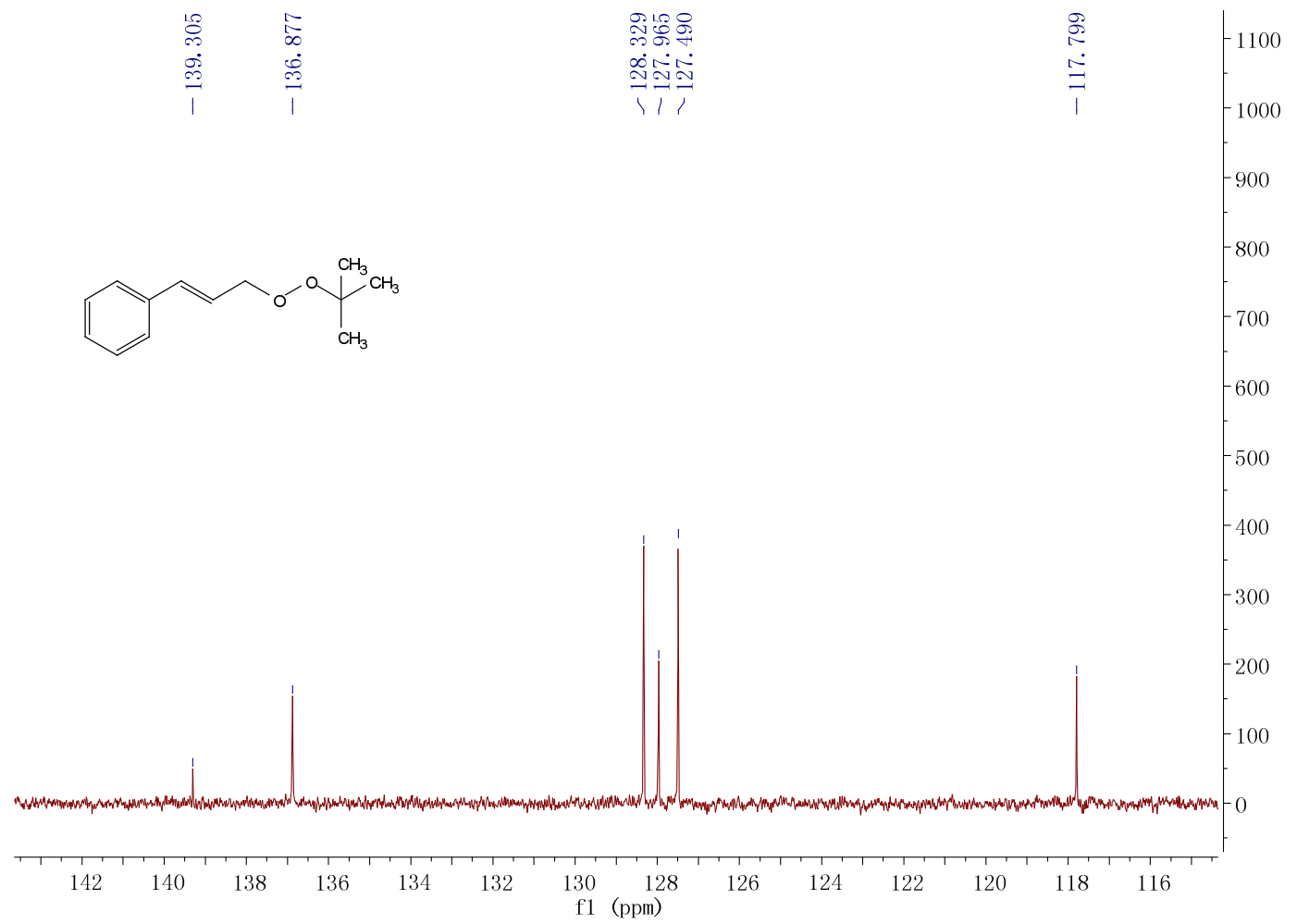

\section{1-((E)-3-(tert-butylperoxy)prop-1-enyl)-4-fluorobenzene (5b)}

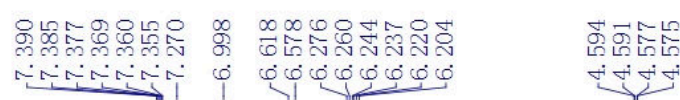<smiles>CC(C)(C)OOC/C=C/c1ccc(F)cc1</smiles>

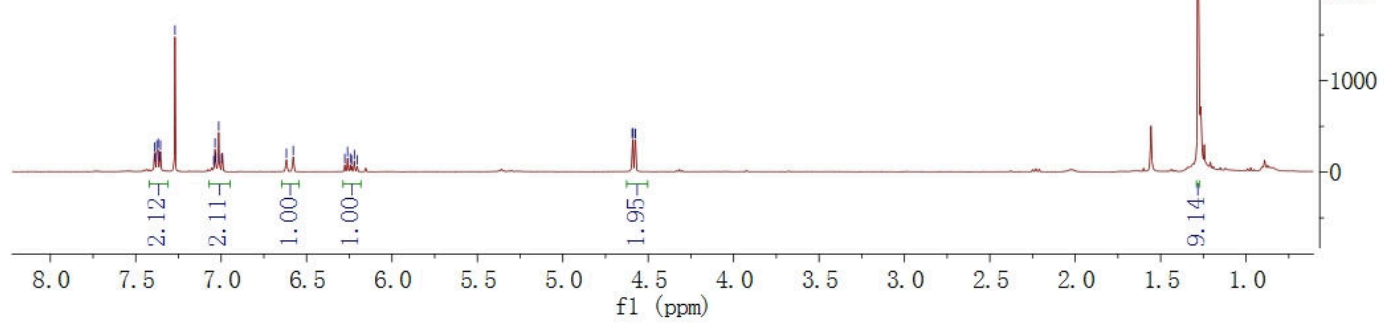




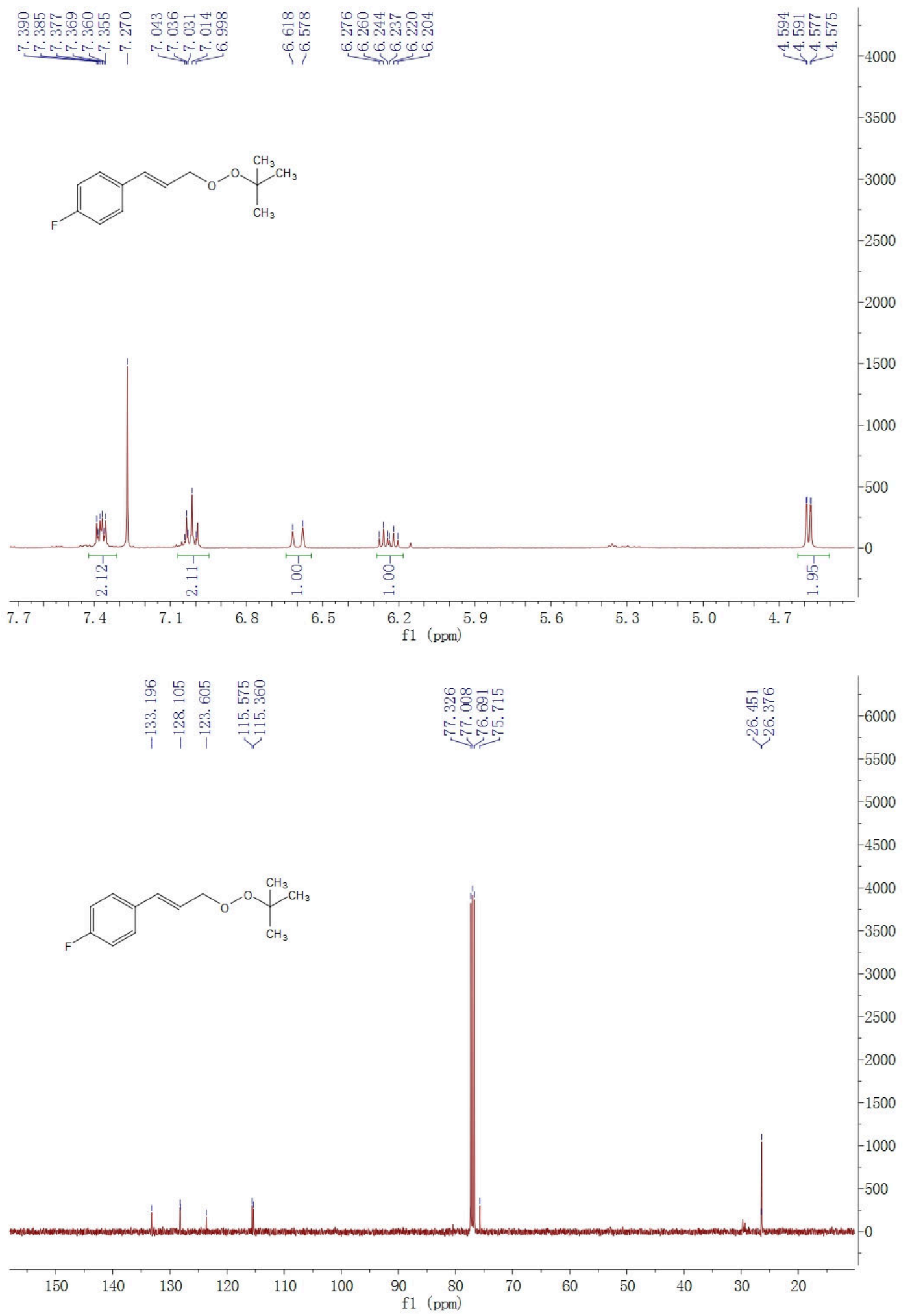




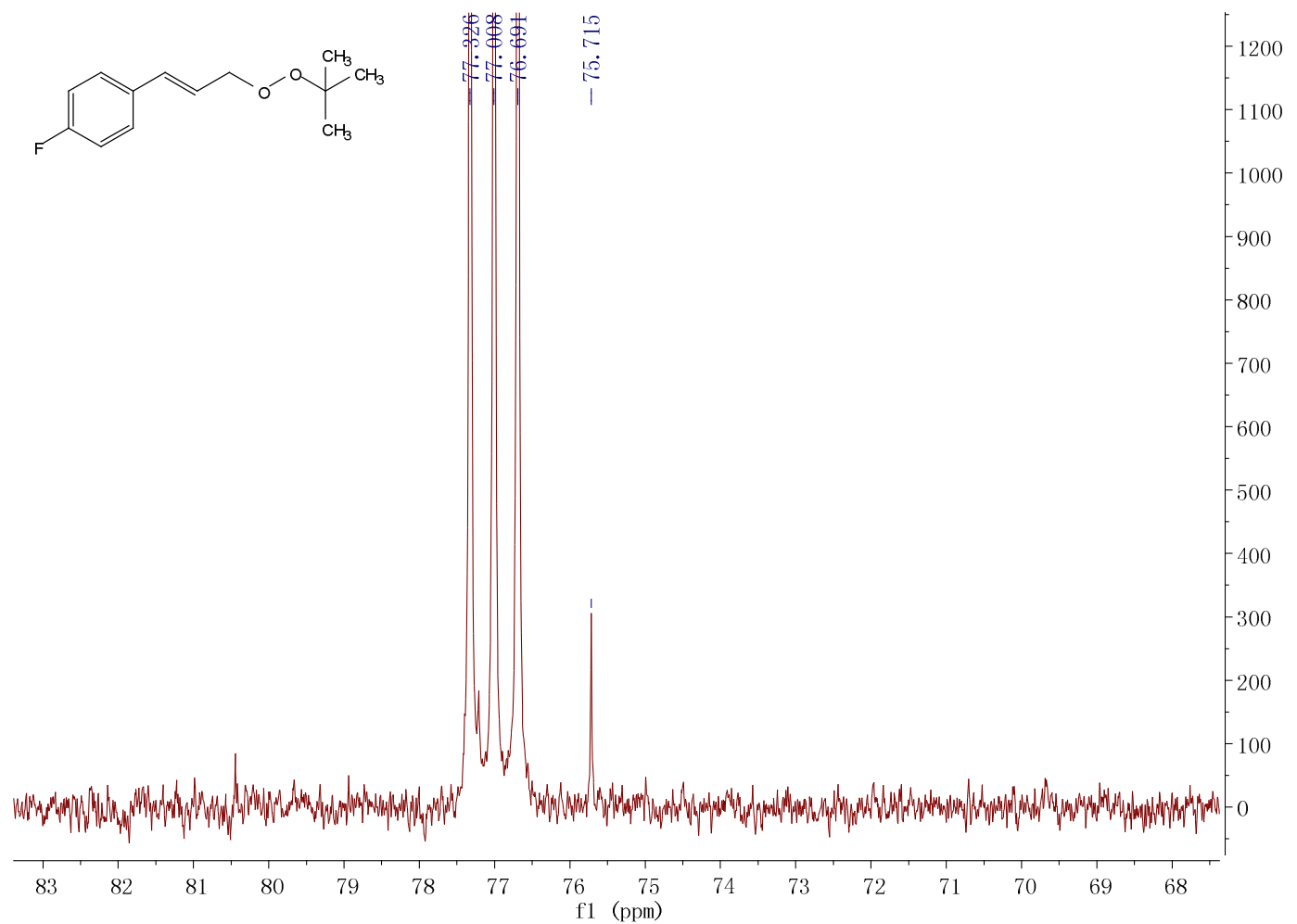

1-((E)-3-(tert-butylperoxy)prop-1-enyl)-4-(trifluoromethyl)benzene (5c)

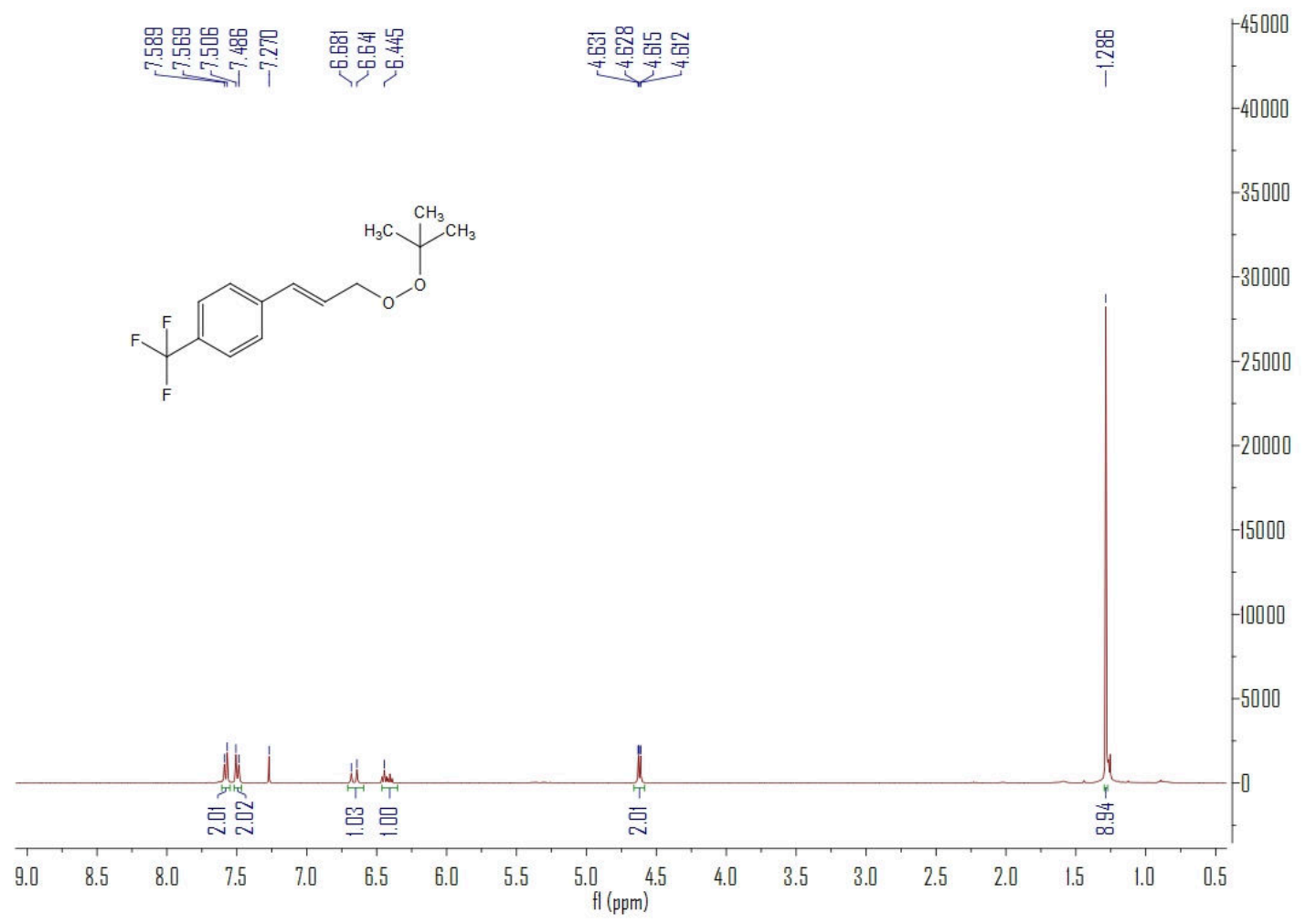




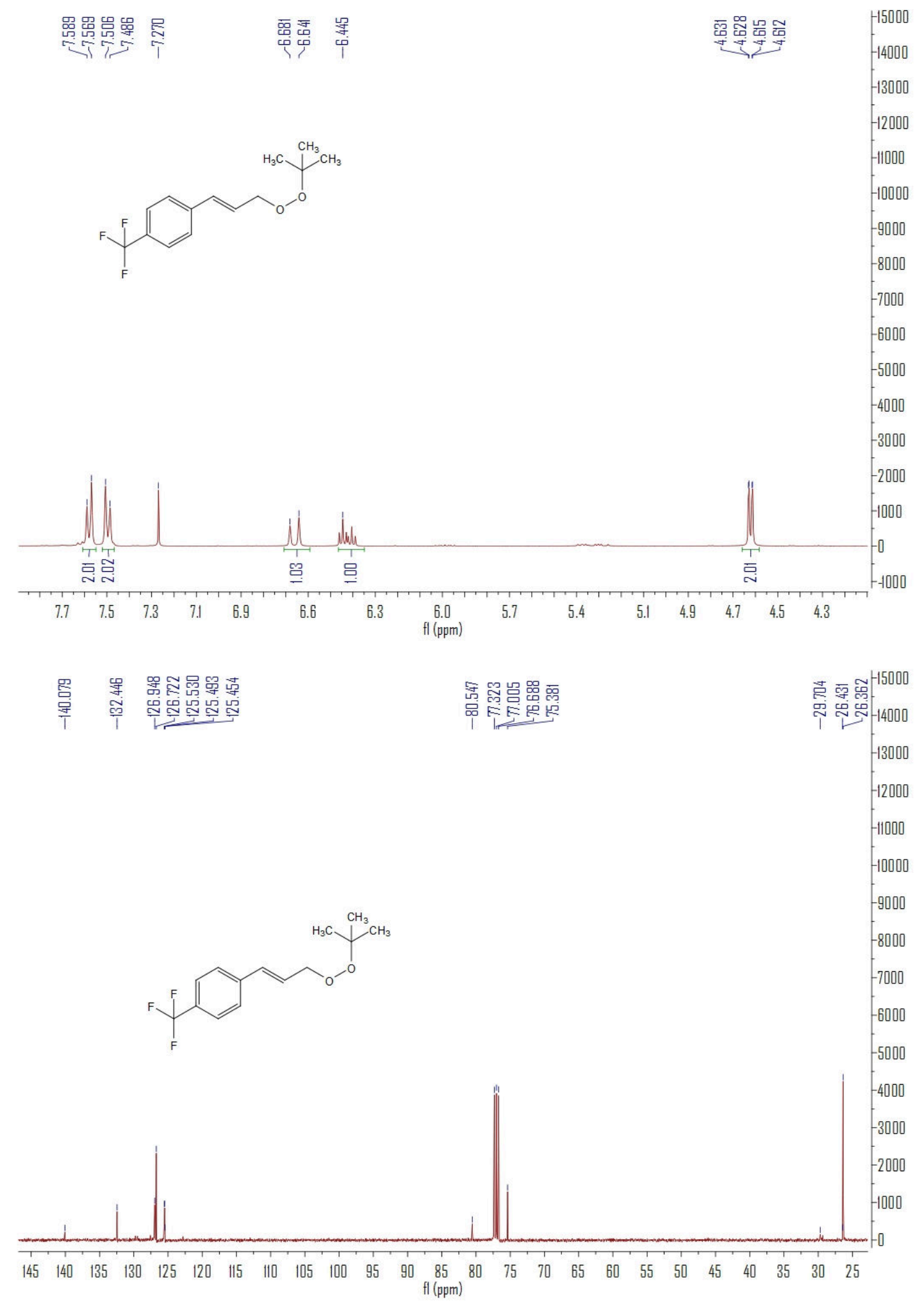




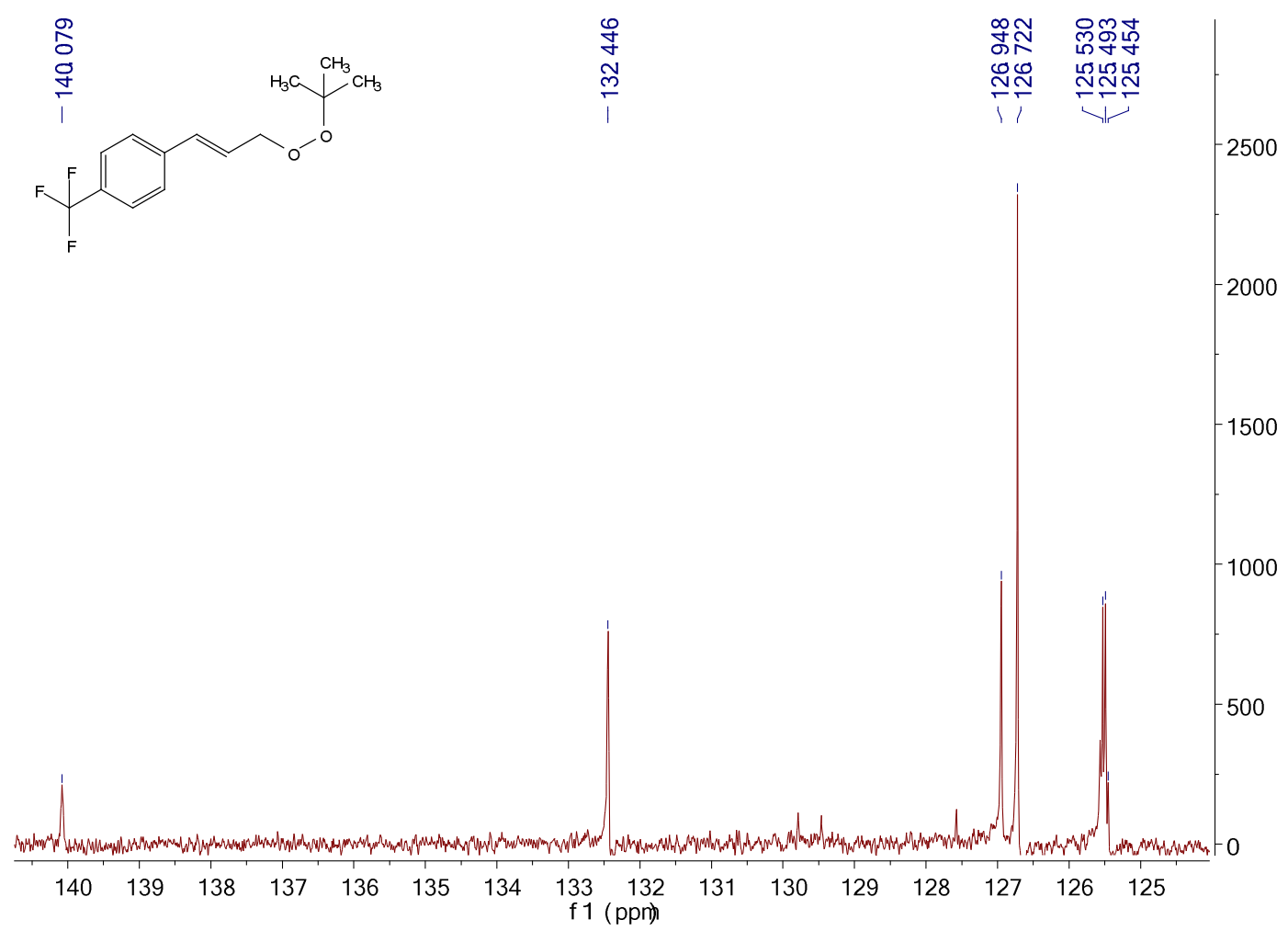

1-((E)-3-(tert-butylperoxy)prop-1-enyl)-2-methoxybenzene (5d)

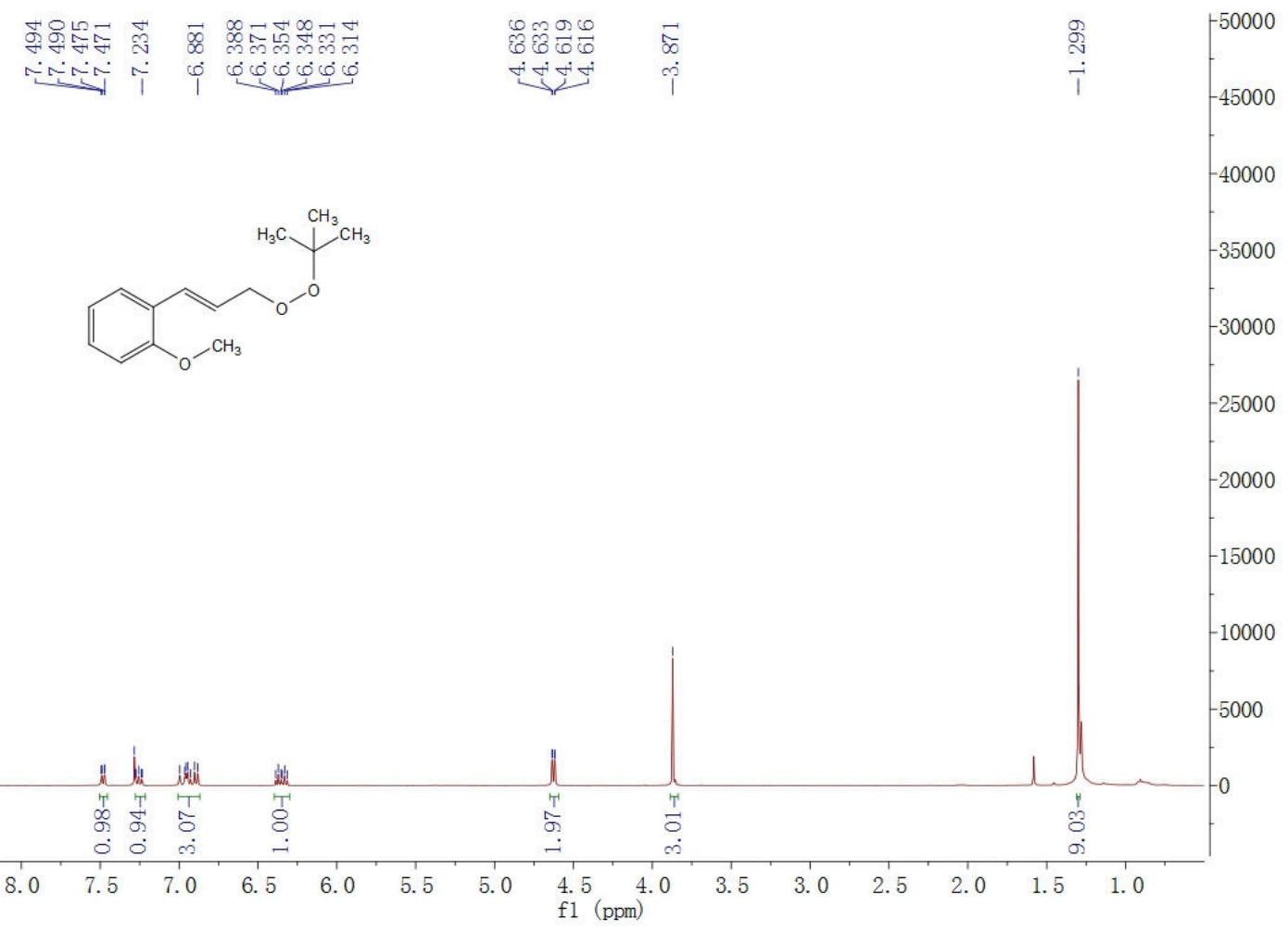




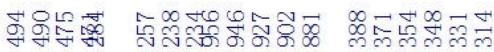

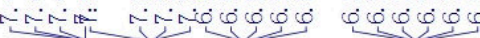

है०

ザザザ

$\begin{array}{ll}\vec{\infty} & +14000 \\ 0 & -13000 \\ i & -12000\end{array}$<smiles>COc1ccccc1/C=C/COC(C)(C)C</smiles>

$-11000$

10000

9000

8000

7000

6000

5000

4000

$-3000$

$-2000$

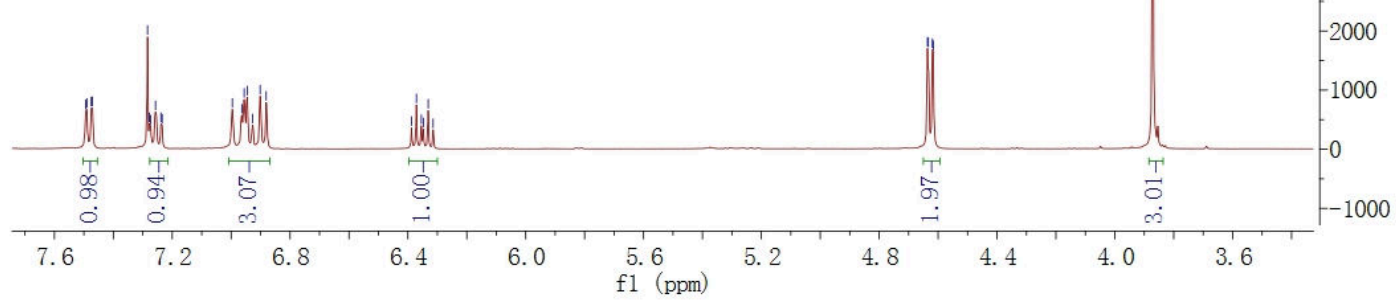

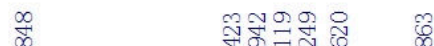

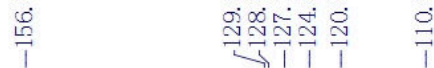

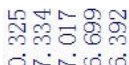

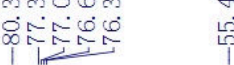
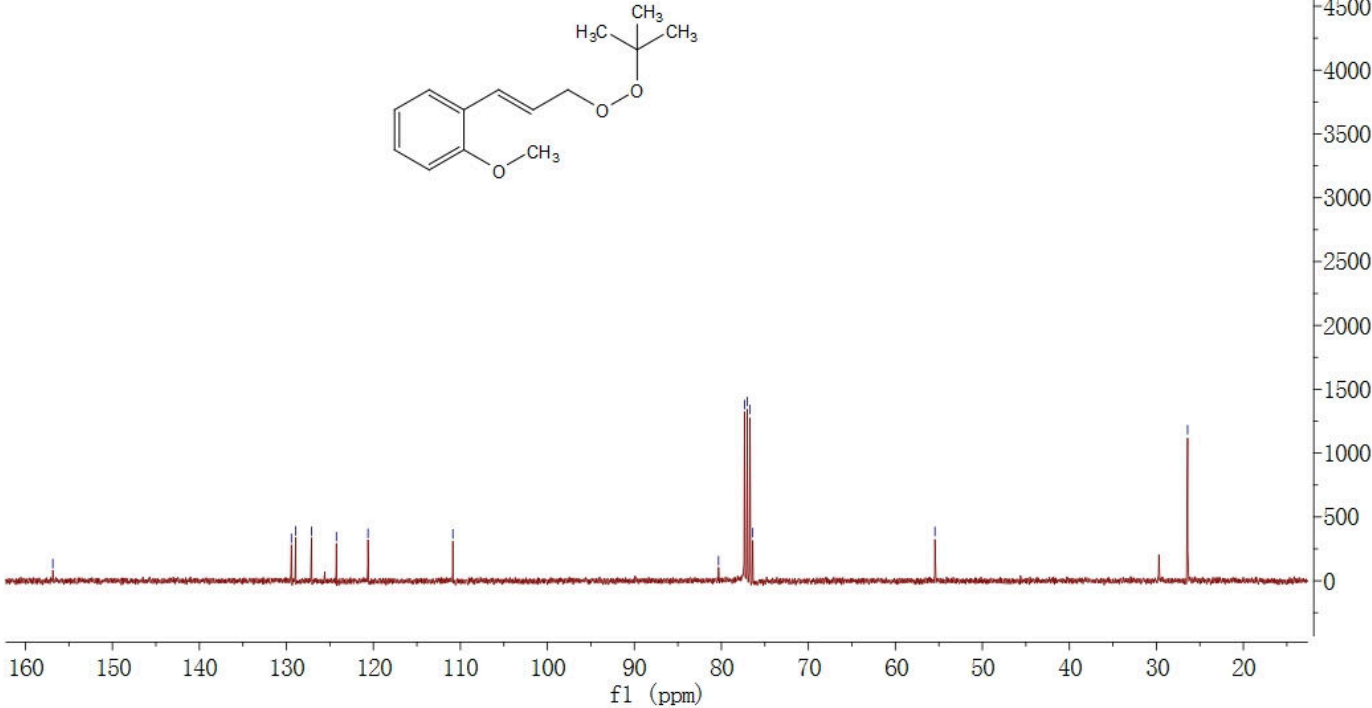


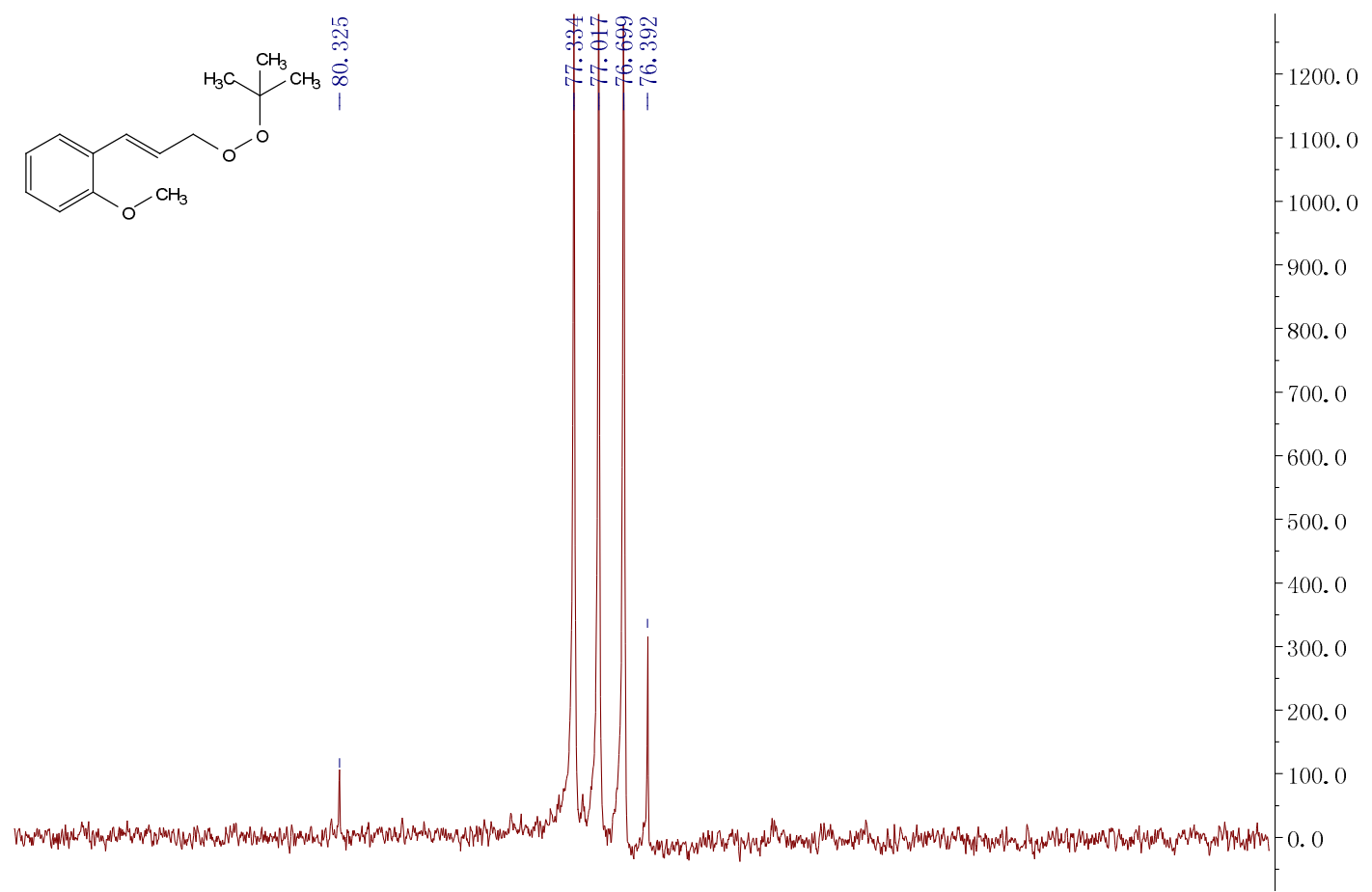

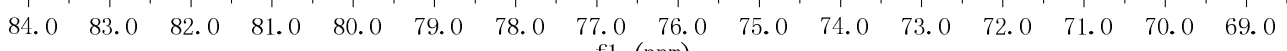

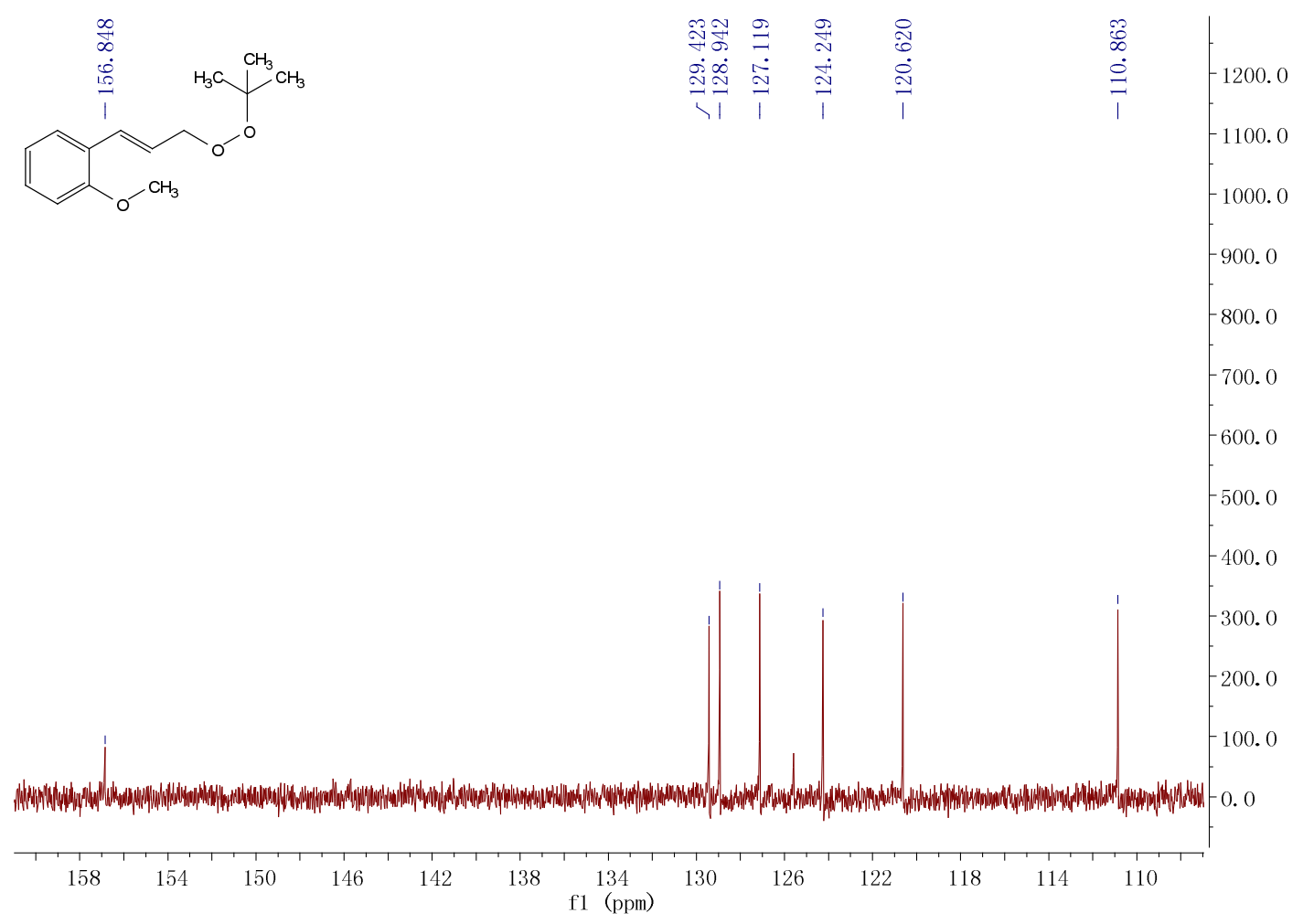




\section{References}

1. Sosa, J. R.; Tudjarian, A. A.; Minehan, T. G. Synthesis of alkynyl ethers and low-temperature sigmatropic rearrangement of allyl and benzyl alkynyl ethers. Org. Lett.2008, 10, 5091.

2. Rilatt, I.; Mirabel, E.; Grand, B. L.; Perez, M.Discovery and SAR of small molecule PAR1 antagonists.Bioorg. Med. Chem. Lett.2010, 20, 903. 